\title{
EO-1 Hyperion Reflectance Time Series at Calibration and Validation Sites: Stability and Sensitivity to Seasonal Dynamics
}

\author{
Petya K. Entcheva Campbell, Elizabeth M. Middleton, Kurt J. Thome, Raymond F. Kokaly, Karl Fred Huemmrich,
} David Lagomasino, Kimberly A. Novick, and Nathaniel A. Brunsell

\begin{abstract}
This study evaluated Earth Observing 1 (EO-1) Hyperion reflectance time series at established calibration sites to assess the instrument stability and suitability for monitoring vegetation functional parameters. Our analysis using three pseudo-invariant calibration sites in North America indicated that the reflectance time series are devoid of apparent spectral trends and their stability consistently is within $2.5-5$ percent throughout most of the spectral range spanning the $12+$ year data record. Using three vegetated sites instrumented with eddy covariance towers, the Hyperion reflectance time series were evaluated for their ability to determine important variables of ecosystem function. A number of narrowband and derivative vegetation indices (VI) closely described the seasonal profiles in vegetation function and ecosystem carbon exchange (e.g., net and gross ecosystem productivity) in three very different ecosystems, including a hardwood forest and tallgrass prairie in North America, and a Miombo woodland in Africa. Our results demonstrate the potential for scaling the carbon flux tower measurements to local and regional landscape levels. The VIs with stronger relationships to the $\mathrm{CO}_{2}$ parameters were derived using continuous reflectance spectra and included wavelengths associated with chlorophyll content and/or chlorophyll fluorescence. Since these indices cannot be calculated from broadband multispectral instrument data, the opportunity to exploit these spectrometer-based VIs in the future will depend on the launch of satellites such as EnMAP and HyspIRI. This study highlights the practical utility of space-borne spectrometers for characterization of the spectral stability and uniformity of the calibration sites in support of sensor cross-comparisons, and demonstrates the potential of narrowband VIs to track and spatially extend ecosystem functional status as well as carbon processes measured at flux towers.
\end{abstract}

Index Terms-Earth Observing-1, eddy covariance, flux sites, forest, grassland, Hyperion, imaging spectroscopy, Pseudo-Invariant Calibration Sites, reflectance, remote sensing, seasonal carbon dynamics, spectral time series, vegetation function, woodland.

Manuscript received March 15, 2012; revised July 20, 2012 and November 02, 2012; accepted November 25, 2012. Date of publication April 24, 2013; date of current version May 13, 2013. This work was supported by the U.S. Department of Energy (DOE) through the Office of Biological and Environmental Research (BER) Terrestrial Carbon Processes (TCP) program (Grants 10509-0152, DE-FG02-00ER53015, and DE-FG02-95ER62083).

P. K. E. Campbell and K. F. Huemmrich are with the University of Maryland Baltimore County, NASA/GSFC, Greenbelt, MD 20771 USA (corresponding author, e-mail: petya.campbell@nasa.gov).

E. M. Middleton and K. J. Thome are with the NASA/GSFC, Goddard Space Flight Center, Greenbelt, MD

R. F. Kokaly is with the USGS, Denver, CO

D. Lagomasino is with the Florida International University, Miami, FL.

K. A. Novick is with the USDA Forest Service, Coweeta Hydrologic Laboratory, Otto, $\mathrm{NC}$.

N. A. Brunsell is with the Department of Geography, University of Kansas, Lawrence, KS.

Color versions of one or more of the figures in this paper are available online at http://ieeexplore.ieee.org.

Digital Object Identifier 10.1109/JSTARS.2013.2246139

\section{INTRODUCTION}

W ITH the changing climate, it has become critical to understand land cover dynamics as ecosystems cycle through seasonal changes and respond to variable environmental conditions. The ability to monitor ecosystem carbon accumulation is of great interest when evaluating the carbon balance between various ecosystems. Long term satellite observations and land cover records are required for such environmental monitoring and change detection. However, multi-date satellite monitoring of the terrestrial environment requires adequate radiometric stability of the data to carry out biophysical and geophysical parameter surveys that are of sufficient sensitivity and accuracy, and are reproducible over time.

The Hyperion ${ }^{1}$ spectrometer carried on the Earth Observing One (EO-1) satellite has provided a rich high resolution data record over more than a decade (2001-2012+). Hyperion spectra cover the 400 to $2500 \mathrm{~nm}$ range with 242 overlapping spectral bands (196 of which are well calibrated) at approximately $10 \mathrm{~nm}$ spectral resolution and $30 \mathrm{~m}$ spatial resolution, typically imaging a $7 \mathrm{~km} \mathrm{x}>100 \mathrm{~km}$ scenes. Use of these hyperspectral images to characterize terrestrial surface states and processes has rapidly increased since 2009, when the EO-1 Hyperion archive was made available at no cost by United States Geological Survey (USGS) [1]. Hyperion data have several advantages over multispectral satellite systems: they provide information critical for atmospheric correction of top of atmosphere (TOA) radiances to derive surface reflectance, they enable the use of a broad array of spectral indices derived throughout the continuous spectra, and they provide the ability to simulate bands equivalent to broadband systems covering similar spectral ranges [2].

Hyperion data have been successfully used in discriminating among land cover types and species groups [3], deriving VIs [2], [4], estimating biophysical products such as forest canopy nitrogen [5], [6], primary production [6], forest canopy closure [7], vegetation fractional cover [8], [9], and canopy biophysical properties such as greenness, wetness and pigment content [10].

Earlier studies, describing the signal to noise ratio (SNR) of Hyperion's radiance measurements in comparison to AVIRIS, the Landsat series and others [10]-[14], have found the data comparable to $\sim 1990$ Airborne Visible/Infrared Imaging Spectrometer (SNR $\sim 160: 1$ in the $0.4-1.0 \mu \mathrm{m}$; and $\sim 40: 1$ in the

\footnotetext{
${ }^{1}$ Any use of trade, firm, or product names is for descriptive purposes only and does not imply endorsement by the U.S. Government.
} 
1.0-2.5 $\mu \mathrm{m})$. Aggregating the 10-nm Hyperion bands into simulated ETM+ multispectral bands has allowed radiometric cross calibration between the Hyperion and Landsat ETM+, or MODIS data, for comparison and conformation of the obtained results [15]. However, most of these studies analyzed individual images, or carefully selected scenes from the same season. In 2008, the EO-1 mission expanded the collection of time series for calibration and validation efforts, to assemble datasets essential for vegetation assessments. Currently there are collections of ten or more images at select sites with eddy covariance towers for examining the dynamics of various land covers at high spectral and spatial resolutions [1].

The goal of this study is to assess the potential of Hyperion reflectance time series to describe seasonal changes in ecosystem functioning. Specific objectives include: 1) evaluation of the temporal stability of Hyperion's reflectance measurements over three pseudo-invariant calibration sites (PICS) which have little seasonal variation in land cover, and 2) quantification of the relationships between VIs from Hyperion's reflectance time series and ecosystem carbon accumulation (e.g. Net and Gross Ecosystem Production), measured over three validation flux sites (VFS) which have strong and very different seasonal leaf area index patterns.

The incoming surface radiance signal is subject to several factors that influence the stability and sensitivity of Hyperion (and any orbital) spectral data. These include sensor shortcomings such as relatively low SNR, and deficiencies in the information and algorithms utilized in initial calibration and processing streams (e.g., standards, measurements, models and accuracy of calibrations performed along the data processing chain). To study surface properties using imaging spectrometer data, accurate removal of atmospheric absorption and scattering effects (e.g., through implementation of atmospheric correction routines) is necessary to derive surface reflectance from top of atmosphere (TOA) radiances. These procedures account for the differences in solar illumination during the year at various locations and correct for differences in atmospheric conditions at the time of acquisition [16]. However, they may also introduce variations into the reflectance data, due to differences between the modeled and real atmospheres at the time the data were collected [2], [16]. As a result, the cumulative error may lead to a variation in the reflectance signal of several percent in each spectral band, which could severely limit the sensitivity of the data, and/or introduce an apparent spectral trend.

Vegetation properties are often assessed by computing VIs using a combination of two or more spectral bands. VIs are designed to relate more clearly to biophysical variables (e.g., chlorophyll, water content) than the original bands alone [17]. Also they tend to minimize variations not related to the variables of interest, such as illumination levels [4], [17]. VIs have been applied to the characterization of vegetation cover using broadband systems, but have even more robust application using hyperspectral data and specific narrowbands for the estimation of vegetation function (e.g., stress, water and light use efficiency, and chlorophyll fluorescence parameters) [5], [17], [19] and a range of leaf-level traits (e.g., pigments, cellulose and water content) [5], [18]-[21]. Roberts et al. [4] summarized VIs into three general categories of vegetation properties: structural, bio- chemical, and plant function/stress. Recent reviews of hyperspectral VIs [4], [17] note that their use with reflectance time series remains to be thoroughly examined.

\section{METHODS}

\section{A. Study Sites}

To assess the stability of the Hyperion reflectance spectra we used three desert calibration sites and three vegetated validation sites. The vegetated sites were selected to provide a variety of vegetation types.

1) Pseudo-Invariant Calibration Sites (PICS): The three desert Pseudo-Invariant Calibration Sites (PICS) are located in the western USA and include: Frenchman Flat (FMF), Ivanpah Playa (IP) and Railroad Valley Playa (RRVP). They are characterized by high reflectances, high spatial and temporal uniformity, high sun elevation, and minimal cloud cover. The PICS (Table I) are among the sites endorsed by the Committee on Earth Observing Satellites (CEOS, http://www.ceos.org/) as standard references for the post-launch calibration of space-based optical imaging sensors [22]. The FMF site is situated in the homogeneous section of the Frenchman Flat dry lakebed located NNE of Mercury, Nevada, USA on the Nevada Test Site range. It serves as The LED-based Spectral (LSpec) vicarious calibration test site [23]. The site is also included in the Aerosol Robotic Network (AERONET [24]), and is ideal for use with sensors with less than $300 \mathrm{~m}$ pixel size. The IP site is a dry-lake playa, located in the Prim Valley on the border of California and Nevada, USA and is large enough for use with mid spatial resolution sensors $(\sim 1 \mathrm{~km})$. The RRVP site is located in a large dry lakebed in central Nevada, approximately 300 miles north of Las Vegas and 100 miles east of Tonopah, and has a dry climate typical of the high desert of western USA [25]. Because of its large size, RRVP is suitable for sensors with even larger footprints $(1-10 \mathrm{~km})$, and is automated with instrumentation used extensively for the vicarious calibration of terrestrial imaging sensors covering the visible (VIS), near-infrared (NIR) and shortwave infrared (SWIR) wavelength ranges [26], [27].

The surface layers and composition of all three sites are relatively smooth and spatially homogeneous, consisting of compacted clay-rich lacustrine deposits [22]. All sites suffer from the presence of iron $\left(\mathrm{Fe}^{3+}\right)$ absorption features, which effects the spectral properties and is a typical characteristic of playas in this region of the USA [22], [25]. Compared to RRVP, the surface layers at FMF and IP contain less loose sand and evaporate salts, and are therefore more stable and spatially uniform [22], [25]-[28].

2) Vegetated Validation Flux Sites (VFS): The selected Validation Flux Sites (VFS) are located in Konza Prairie near Manhattan, Kansas, USA, the Duke Forest near Durham, North Carolina, USA, and Mongu, Zambia in Africa. Their characteristics are also described in Table I. The vegetated sites were part of the FLUXNET network, and had instrumented towers providing meteorological and eddy covariance data (Table I). The Konza and Mongu VFS are a part of the network of Earth Observing System (EOS) Land Validation Core Sites for land product validation. 
TABLE I

Description of Calibration and Validation Study Sites: Location AND Land Cover Type/SPECIES Composition

\begin{tabular}{|c|c|c|c|c|}
\hline Site Name & $\begin{array}{c}\text { Center } \\
\text { Latitude }\end{array}$ & $\begin{array}{c}\text { Center } \\
\text { Longitude }\end{array}$ & $\begin{array}{c}\text { Elevation } \\
\left(\mathrm{m} \text { asl }{ }^{+}\right)\end{array}$ & Land Cover and Vegetation Type \\
\hline $\begin{array}{l}\text { Frenchman } \\
\text { Flat, NV, USA }\end{array}$ & 36.80928 & -115.93479 & 940 & Playa, no vegetation \\
\hline $\begin{array}{l}\text { Ivanpah Playa } \\
\text { CA, USA }\end{array}$ & 35.5692 & -115.3976 & 813 & Playa, no vegetation \\
\hline $\begin{array}{l}\text { Railroad Valley } \\
\text { NV, USA } \\
\end{array}$ & 38.50 & -115.69 & 1435 & Playa, no vegetation \\
\hline $\begin{array}{l}\text { Duke Forest } \\
\text { NC, USA }\end{array}$ & 35.973583 & -79.100433 & 170 & $\begin{array}{l}\text { Mixed Hardwoods: Carya tomentosa, C. glabra, } \\
\text { Liriodendron tulipifera, Liquidambar styraciflua, } \\
\text { and oaks (Q. alba, } Q \text {. michatxii, } Q \text {. phellos); } \\
\text { Loblolly plantation: Pinus taeda } L \text {. }\end{array}$ \\
\hline $\begin{array}{l}\text { Konza, KZ } \\
\text { USA }\end{array}$ & 39.080002 & -96.559998 & $320-440$ & $\begin{array}{l}\text { Tallgrass prairie, } \mathrm{C} 4 \text { grasses: Andropogon } \\
\text { gerardii, Sorghastrun nutans, Panicum virgatum, } \\
\text { Schizachyrium scoparium }\end{array}$ \\
\hline Mongu, Zambia & -15.4377 & 23.2527 & 1080 & $\begin{array}{l}\text { Miombo Woodland: Brachystegia bakerianal } \\
\text { Brachystegia spiciformis }(95 / 5 \%)\end{array}$ \\
\hline
\end{tabular}

The Duke Forest (North Carolina, USA) study site includes two adjacent ecosystems, with flux towers operating during 2001-2010 by Duke University. One of the towers was located in an even-aged $20+$ year-old loblolly pine (LP) plantation and the other in a mixed hardwood stand (HW). The two forests differ in predominant vegetation cover type and canopy structures, while experiencing nearly identical climatic and edaphic conditions. The LP site was established in 1983 following a clear cut and a burn events [28], [29], and is comprised primarily of $P$. taeda with some emergent Liquidambar styraciflua $L$. and a diverse sub-canopy. The mixed HW mature forest is a 90-110-year old stand, dominated by oaks (Quercus alba L., Q. michauxii Nutt., Q. phellos L.) and hickories (Carya tomentosa (Poir.) Nutt., C. glabra (P. Mill). Sweet.), with some yellow poplar (Liriodendron tulipifera L.) and sweetgum (Liquidambar styraciflua L.) [28], [29].

The Konza Prairie site (Kansas, USA, Table I) includes two flux towers located in grasslands managed under one- and fouryear burn cycles [30]-[32]. The vegetation is primarily (>90\%) native tallgrass (TG) prairie species dominated by perennial $\mathrm{C}_{4}$ grasses such as Andropogon gerardii, Sorghastrun nutans, Panicum virgatum and Schizachyrium scoparium. However, numerous sub-dominant grasses, forbs and woody species contribute to the high floristic diversity of the Konza Prairie site [30], [31]. It has a continental climate characterized by warm, wet summers and dry, cold winters. The mean annual precipitation of $835 \mathrm{~mm}$ is sufficient to support woodland or savanna vegetation. Consequently, drought, fire and grazing are important in maintaining this topographically complex grassland [31], [32].

The African validation site near Mongu, Zambia (Table I) is monitored by one eddy covariance tower located in a forested area [33], [34] where flux measurements have been acquired since 2008 . The site is dominated by hardwood trees and referred to as Miombo woodland (MW) with a fractional cover of $65 \%$ as measured by Scholes et al. [35]. Grass cover is minimal [33] with the remaining surface area consisting of bare aeolian sand. Canopy cover heterogeneity is largely the result of disturbances associated with subsistence forestry, grazing, and fire, which contribute to the patchiness of the land surface. Based on a 20-yr average (1973-93) mean annual rainfall for Mongu was $879 \mathrm{~mm}$, with $94 \%$ of this amount received during the wet season months of October-March [34].

\section{B. Data Collections and Processing}

1) EO-1 Hyperion Time Series Collection: The Hyperion image collection in the 2001-2011 timeframe over the study sites is comprised of more than 350 images with varying extents of cloud cover. The comparisons and analyses were restricted to cloud-free $(<20 \%)$ data with a maximum of five degrees difference in sensor viewing geometry. The optimal Hyperion images (Table II) were selected and downloaded as calibrated at-sensor radiances from the USGS (EarthExplorer, http://earthexplorer.usgs.gov/), and processed using ENVI [36], ERDAS Imagine [37] and PRISM [38].

The TOA radiances measured by Hyperion were converted to surface reflectances, using the commercially-available software, Atmosphere CORrection Now (ACORN) [39], designed for pushbroom imaging spectrometers with cross-track spectral calibration variation. ACORN uses the MODTRAN4 [40] radiative transfer model, constrained by the elevation and the observation geometry, to explicitly simulate the absorption and scattering effects of atmospheric gases and aerosols, in order to produce apparent surface reflectance. A key characteristic of ACORN is the use of full spectral fitting methods to solve for the overlap of absorptions between water vapor and liquid water in surface vegetation [39]. From calibrated Hyperion radiances, the ACORN routine (mode $1 \mathrm{pb}$ ) produced a high spectral resolution apparent surface reflectance image cube and a water vapor single-band image for each acquisition (Table II) estimated on a pixel-by-pixel basis using the absorption bands at 940 and $1150 \mathrm{~nm}$. Both transmitted radiance and atmospheric reflectance were calculated for each pixel using the derived water vapor, atmospheric pressure, site elevation, and aerosol optical depth estimates. Apparent surface reflectance was derived using either mid-latitude summer or winter atmospheric models [39] depending on the acquisition date and site location. ACORN offers artifact (e.g., spectrally incoherent noise) suppression options, which were not employed in order to preserve original spectral variability. Also, the images were not geographically or geometrically rectified. 
TABLE II

EO-1 Hyperion IMAGES USED IN THIS STUdy

\begin{tabular}{lcc}
\hline \multicolumn{1}{c}{ Site Name } & $\begin{array}{c}\text { Cloud-free } \\
\text { Images } \\
\text { [number (year)] }\end{array}$ & \multicolumn{1}{c}{$\begin{array}{c}\text { Analyzed Scenes by Acquisition Date } \\
\text { [doy/year] }\end{array}$} \\
\hline Frenchman Flat, USA & $6(2003-2009)$ & $\begin{array}{c}12 / 2009,178 / 2003,199 / 2008,219 / 2007,222 / 2008,270 / 2007, \\
337 / 2008 .\end{array}$ \\
Ivanpah Playa, USA & $6(2002-2005)$ & $\begin{array}{c}68 / 2003,81 / 2002,148 / 2003,169 / 2005,180 / 2003,244 / 2003 . \\
12 / 2006,41 / 2006,120 / 2007,135 / 2007,165 / 2001,174 / 2004,\end{array}$ \\
Railroad Valley, USA & $14(2001-2008)$ & $\begin{array}{l}176 / 2008,181 / 2001,197 / 2001,209 / 2007,234 / 2006, \\
272 / 2005,284 / 2005,288 / 2007 .\end{array}$ \\
\hline Duke (HW and Pines), USA & $7(2008-2009)$ & $6,34,162,180,203,290,300$. \\
Konza Prairie, USA & $7(2008-2009)$ & $13,28,202,205,261,266,302$. \\
& & $22,40,107,115,141,145,158,163,171,173,176,181,191$, \\
Mongu, Zambia & $25(2008-2009)$ & $194,199,201,204,225,230,253,284,291,296,302,365$. \\
& & \\
\hline
\end{tabular}

TABLE III

SUBSET OF HYPERION 224 BANDS TO 171 AT PICS AND 159 VFS

\begin{tabular}{|l|c|c|c|c|}
\hline \multirow{2}{*}{ Array } & Pseudo Invariant Cal. Sites (PICS) & \multicolumn{2}{c|}{ Vegetative Sites } \\
\cline { 2 - 5 } & Bands & Wavelengths (nm) & Bands & Wavelengths (nm) \\
\hline VNIR & $8-57(49)$ & $426-926$ & $16-57(49)$ & $498-926$ \\
\hline SWIR1 & $79-120(41)$ & $993 ;-1346$ & $78-120(41)$ & $993 ;-1346$ \\
\hline SWIR2 & $129-165(36)$ & $1518-1800$ & $137-164(27)$ & $1518-1790$ \\
\hline SWIR3 & $179-224(45)$ & $1942-2395$ & $198-213(42)$ & $2133-2285$ \\
\hline Total & $(171)$ & & $(159)$ & \\
\hline
\end{tabular}

Band subsetting was used to remove uncalibrated and overlapping bands, and bands with low SNR and high variability (e.g., bands adjacent to water absorption features), resulting in subsets of 171 bands for PICS and 159 for VFS, covering portions of the VIS, NIR and SWIR regions (Table III). The smaller spectral band subset at the VFSs is due to the stronger effect of canopy water absorption features on the adjacent bands, causing errors in the atmospheric correction procedure. Bands in wavelength ranges around $1430 \mathrm{~nm}$ and $1930 \mathrm{~nm}$ were also eliminated due to strong disturbance by atmospheric water vapor.

Local spatial statistics were used to discern spatially homogeneous areas for spectral extraction at the PICS. We evaluated spatial uniformity for all dates by calculating the Getis $\operatorname{Ord}\left(\mathrm{G}_{\mathrm{i}}\right)$ statistics and Moran's I index in ENVI [41]. A cluster of pixels with high (or low) digital count values is indicated by largely positive (or negative) $G_{i}$ values [36], [41]. Moran's I index, a measure of local spatial uniformity, ranges between +1 and -1 , where +1 defines spatially correlated pixels (i.e. those with clustered data values) and -1 spatially uncorrelated data (i.e., pixel values with no clustering). We also calculated mean reflectance at each band and used the coefficient of variation (CV) and the ratio of the standard deviation (SD) over the mean (x) [22], to characterize the radiometric and temporal stability for each band.

We identified the position of the FLUXNET sites on the images using available maps, photos and images. Spectra were extracted, from corresponding areas, from 20-30 pixels within the Hyperion images. We calculated mean reflectance at each band and used the coefficient of variation (CV) and the ratio of the standard deviation (SD) over the mean (x), to characterize the temporal variation for each band. The slight shifts in the overlay of the pixels of spectral extraction on the ground unavoidably introduce statistical uncertainty and random variation, which maybe more pronounced at the Mongu site, where the woodland canopy cover is more sparse and variable. We chose to retain the nearly full-spectral range of Hyperion data, in order to test the ability of the band depth analysis and spectral VIs to detect changes in vegetation function and to track $\mathrm{CO}_{2}$ seasonal dynamics measured at the FLUX towers.

2) Eddy Covariance Data at Validation Flux Sites (VFS): Net Ecosystem Production (NEP) provides a comprehensive measure of ecosystem net carbon accumulation which is defined as the carbon accumulation within ecosystems and is the difference between gross primary production (GPP) and ecosystem respiration (Re) [42]. NEP is measured with eddy covariance methods using sonic anemometers mounted on towers above the canopies [42]. For each VFS, we assembled a set of data (e.g., NEP and associated meteorological parameters such as precipitation and temperature) covering the timeframe of the Hyperion image acquisitions. For the analysis, the flux data and the Hyperion reflectance were paired by date of acquisition. Data for the Mongu site were downloaded from the CarboAfrica web site (http://www.carboafrica.net/data_en.asp, PI for Mongu Dr. W. Kutsch), and flux data from the other sites were provided by their tower managers Dr. Brunsell (KNZ-LTER) for the Konza Prairie site, and Dr. Kimberly Novick (The School of the Environment at Duke University) for the Duke Forest sites.

Midday flux averages were calculated as the average of the observations collected between 11:00 AM and 1:00 PM local time. The data for Mongu and Konza were not gap-filled. The Duke NC data were gap-filled using methods described in Stoy et al. 2006 [43].

NEP was partitioned into Gross Ecosystem Production (GEP) and Ecosystem Respiration (Re). For the Duke and Konza sites, 
daytime Re was calculated from relationships developed between nighttime NEP and air temperature [44], [45]. For the Mongu site, air temperature alone did not provide a good description of variation in Re, so the Re model used both air temperature and soil moisture. GEP was computed as the sum of NEP and Re.

3) Reflectance Time Series for Validation Sites: The Hyperion time series included multiple scenes in order to construct a phenology season, with many images collected over multiple years. Due to the non-continuous temporal resolution (i.e. tasked and targeted image acquisition) of Hyperion datasets used in this study (Table II), annual documentation of seasonally representative vegetation phenological changes was not possible. However, both spectra and the corresponding eddy covariance $\mathrm{CO}_{2}$ flux measurements were organized in seasonally successive chronological order based on the day of year (DOY), regardless of acquisition year.

4) Continuum Removal and VIs From High Spectral Resolution Spectra: We applied the 'band depth analysis of absorption features' method [46] that enhances and standardizes known spectral chemical absorption features. Continuum removal normalizes reflectance spectra to allow comparison of individual absorption features from a common baseline [38], [46], [47]. The continuum is a straight line segment fitted over the hull of the spectrum, thus connecting the local maxima [46]. The continuum-removed reflectance is obtained by dividing the reflectance value in the absorption minimum by the reflectance level of the continuum line at the corresponding wavelength. The Processing Routines in IDL for Spectroscopic Measurements (PRISM) provide a uniform and automated approach for obtaining continuum removed (CR) Hyperion reflectances, with spectral profile output having values between 0 and 1 for enhancing the selected features [38], [46].

Six known chemical absorption features have been associated with foliar chemistry, including the VIS chlorophyll absorption features $(470-520 \mathrm{~nm}, 550-750 \mathrm{~nm})$, and SWIR absorption features (1110-1285 nm, 1630-1790 nm, 2005-2195 $\mathrm{nm}$, and 2220-2380 nm) detecting water, lignin and cellulose [38], [46], [48]. We applied the band depth analysis to study the seasonal changes in feature depth (FD) in the well-defined chlorophyll absorption feature (between 500-800 nm). Feature depth was computed as

$$
\mathrm{FD}=(1-\mathrm{CR})
$$

where $\mathrm{CR}$ is the continuum removed reflectance at $675 \mathrm{~nm}$, so that increasing amounts of chlorophyll absorber yield increasing FD. We selected this strong feature because it is in a high Hyperion $\mathrm{S} / \mathrm{N}$ region, away from atmospheric water absorption bands, and thus less subject to noise or residual atmospheric contamination.

Recent review articles [4], [17] provide a summary of the utility of VIs derived from high resolution ( $\leq 10 \mathrm{~nm}$ bands) reflectance and derivative spectra [19], [20]. At the VFS, we tested the ability of a subset of reflectance VIs applicable for agriculture and forestry to track the dynamics in vegetation $\mathrm{CO}_{2}$ assimilation parameters (e.g., NEP and GPP). Using the full spectral range of Hyperion, and adjusting the formulas to Hyperion's band centers and $10 \mathrm{~nm}$ resolution, we generated 76 high resolution VIs: 18 for structure (e.g., LAI and biomass), 31 for biochemical content (e. g., chlorophyll, 18; carotenoids, 2; anthocyanins, 2; photosynthetic pigments, 5; water, 3; and lignin and cellulose, 1); 27 for plant function (e.g., stress, 12; light use efficiency, 4; and chlorophyll fluorescence, 11). We were not able to generate VIs that required the use of blue wavelengths below $450 \mathrm{~nm}$ (e.g., SIPI for pigment content), or wavelengths between 1350-1500 $\mathrm{nm}$ (for canopy structure, water content) and 1950-2100 $\mathrm{nm}$ (for lignin and cellulose content), due to the lower data quality at these wavelengths. These 76 useful VIs included band ratios of derivative (typically first derivative) spectra, which have been demonstrated to be strongly related to chlorophyll concentration, chlorophyll fluorescence and forest stress [19], [20]. The first derivatives (D) of reflectance were calculated using the formula:

$$
\mathrm{D}_{\lambda \mathrm{i}}=\frac{\left(\mathrm{R}_{\lambda(\mathrm{i}+1)}-\mathrm{R}_{\lambda(\mathrm{i}-1)}\right)}{\left(\lambda_{(\mathrm{i}+1)}-\lambda_{(\mathrm{i}-1)}\right)}
$$

where $D_{\lambda i}$ is the first derivative and $R_{\lambda i}$ is the mean reflectance value at $\lambda \mathrm{i}$ wavelength. The derivative transformation provides spectral data that are less sensitive to the effects of variable irradiance and the influences of canopy structural and bidirectional properties. To compare the above high spectral resolution VIs with broadband VIs we simulated the bands of Landsat TM (lower spectral resolution), and calculated the most widely used Normalized Difference Vegetation Index (NDVI) and the Enhanced Vegetation Index (EVI).

5) Statistical Analysis: Analysis of Variance routines and descriptive statistics [49] are used to assess temporal spectral uniformity and/or VIs at each site. The resulting mean (x) and standard deviation (SD) statistics are reported as plots for each site and summarized for comparison between the sites. To examine the temporal variability in the spectral properties of VFS, the means and standard deviations for each of the sites were plotted and discussed further in the results section. Also at the VFS, analyses of variances and regression procedures were used to relate the Hyperion VIs to NEP and GEP tower measurements [49]. Spectra were analyzed individually for each VFS, as well as collectively as a multi-site dataset.

\section{RESULTS}

\section{A. Seasonal Dynamics of Hyperion Reflectance at Pseudo-Invariant Calibration Sites (PICS)}

The $\mathrm{G}_{\mathrm{i}}$ statistics and Moran's I index describe the spatial uniformity of the PICS (Figs. 1 and 2, Table IV). The FMF site offers an approximately $2 \times 2 \mathrm{~km}$ area with relatively uniform high reflectance distribution, as determined by the $G_{i}$ statistics (Figs. 1(a), 2(a)). The homogenous area at IP was approximately $2 \times 4 \mathrm{~km}$ (Figs. 1(b), 2(b)). RRVP had an area of approximately $6 \times 10 \mathrm{~km}$ with relatively uniform reflectance (Figs. 1(c), 2(c)). The highest reflectance values were measured across the 650-2000 nm region at FMF, followed by IP and RRVP (Figs. 1, 2). At RRVP, we observed that certain areas of 
(a)
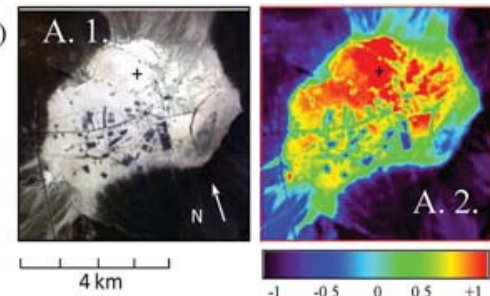

(b)

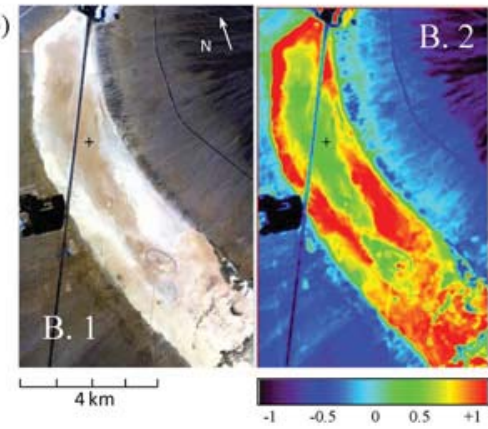

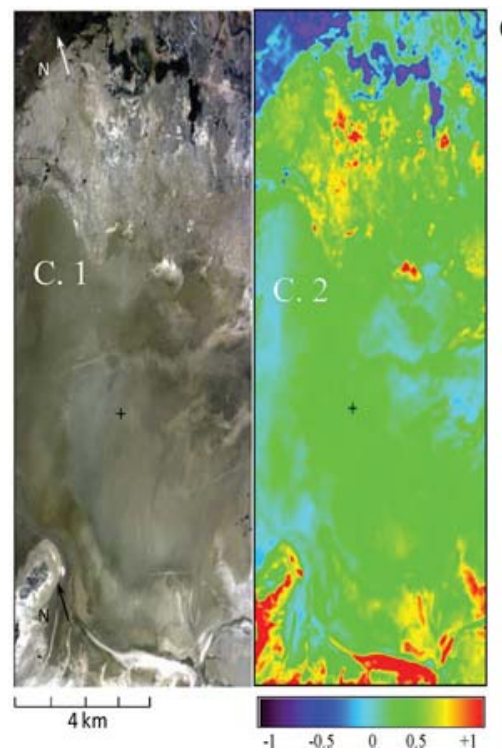

(c)

Fig. 1. Pseudo invariant calibration sites (PICS): (a) Frenchman Flat (FMF), (b) Ivanpah Playa (IP), and (c) Railroad Valley (RRVP). The center of the region (30-40 pixels) of reflectance extraction is marked with a cross. Two portrayals are shown for each site from a summer acquisition: natural color composites (fig. (a)1, (b)1, (c)1; RGB: 651,549,447 nm), and the Getis $\mathrm{G}_{\mathrm{i}}$ statistics calculated to indicate homogeneous pixel clusters (fig. (a)2, (b)2, (c)2).

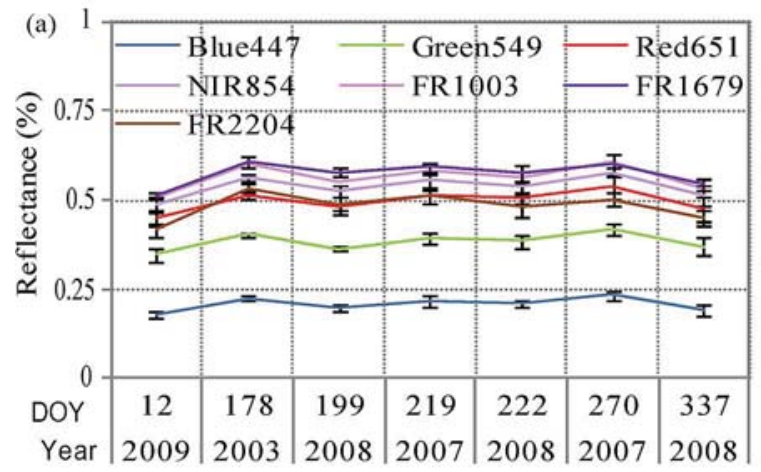

Acquisition Date (DOY, year)

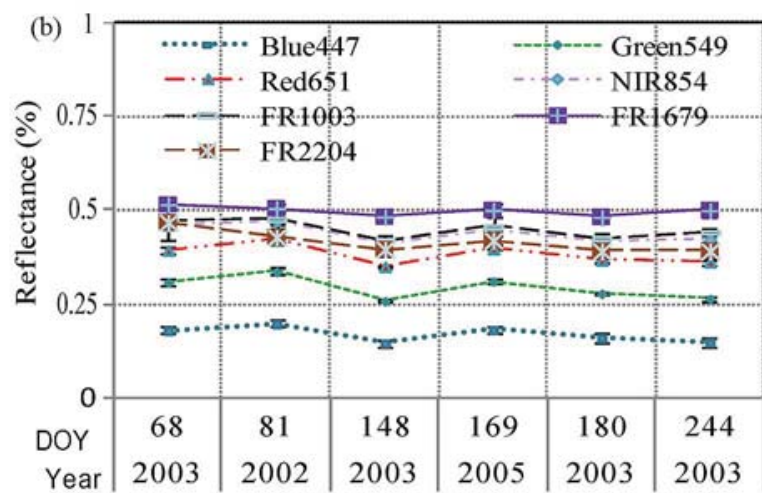

Acquisition Date (DOY, year)

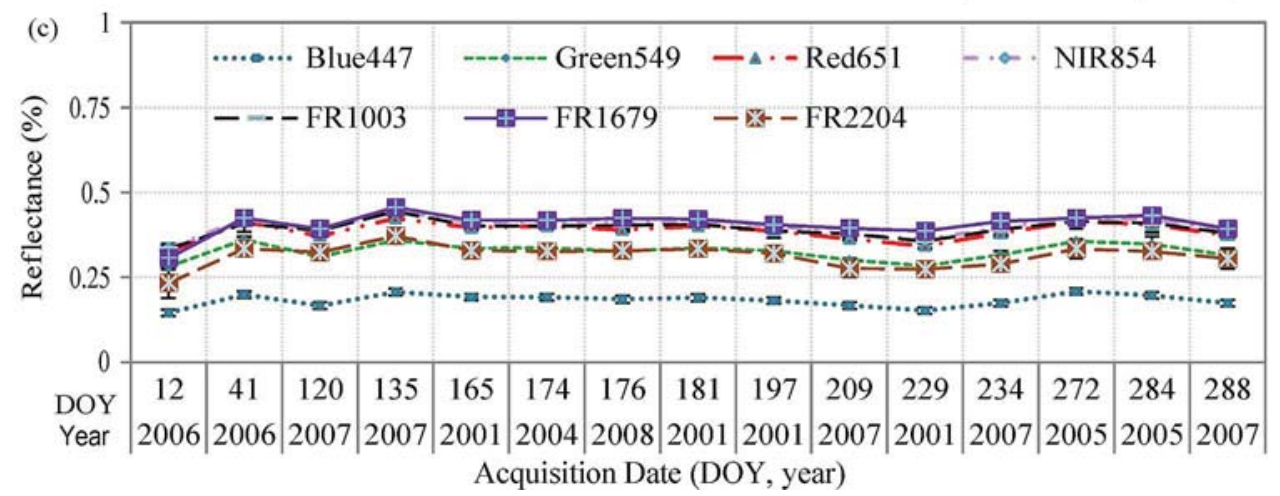

Fig. 2. Temporal variation (X \pm SD) in the Hyperion reflectance at select wavelengths: (a) Frenchman Flat (FMF, 7 images acquired in 2005-2008), (b) Ivanpah (IP, 6 images acquired in 2003-2005) and (c) Railroad Valley (RRVP, 15 images acquired in 2001-2008). The seven Hyperion bands selected to represent the seasonal reflectance trends are centered at: 447, 549, 651, 854, 1003, 1679 and $2204 \mathrm{~nm}$.

the site are brighter than others. Since the site is completely devoid of vegetation, this contrast can be explained by soil moisture effects and variations in the mineral composition of the playa's surface.

The three calibration sites (Fig. 3) can be characterized as having high mean reflectance values, across a wide spectral range, which agrees with previous studies conducted over the same sites using field radiometers and/or space-borne multispectral sensors [12], [14], [37]. Mean reflectance in the blue region $(450-550 \mathrm{~nm})$ was highest at FMF $(25-40 \%, \pm 2.3-2.5 \%$, Fig. 3(a)), lowest at IP (8-12, $\pm 2.1-2.8 \%$, Fig. 3(b)), and intermediate at RRVP (18-28, $\pm 2-2.5$, Fig. 3(c)). 
TABLE IV

Hyperion Reflectance and Moran I Statistics for SeVen WaVElengths at These Pseudo Invariant Calibration Sites (PiCS)

\begin{tabular}{|c|c|c|c|c|c|c|c|c|c|c|c|c|}
\hline \multirow{3}{*}{$\begin{array}{l}\text { Wavelength } \\
\quad(\mathrm{nm})\end{array}$} & \multicolumn{4}{|c|}{ Frenchman Flat } & \multicolumn{4}{|c|}{ Ivanpah Playa } & \multicolumn{4}{|c|}{ Railroad Valley Playa } \\
\hline & \multicolumn{3}{|c|}{ Reflectance (\%) } & \multirow{2}{*}{$\begin{array}{c}\text { Moran's I } \\
( \pm 1)^{*}\end{array}$} & \multicolumn{3}{|c|}{ Reflectance (\%) } & \multirow{2}{*}{$\begin{array}{c}\text { Moran's I } \\
( \pm 1)^{*}\end{array}$} & \multicolumn{3}{|c|}{ Reflectance (\%) } & \multirow{2}{*}{$\begin{array}{c}\text { Moran's I } \\
( \pm 1)^{*}\end{array}$} \\
\hline & Mean & SD & $\mathrm{CV}$ & & Mean & SD & $\mathrm{CV}$ & & Mean & SD & $\mathrm{CV}$ & \\
\hline 447 & 0.21 & 0.020 & 0.095 & 0.97 & 0.17 & 0.021 & 0.122 & 0.94 & 0.20 & 0.019 & 0.095 & 0.86 \\
\hline 549 & 0.38 & 0.024 & 0.063 & 0.98 & 0.29 & 0.031 & 0.105 & 0.97 & 0.34 & 0.025 & 0.074 & 0.87 \\
\hline 651 & 0.50 & 0.028 & 0.056 & 0.97 & 0.38 & 0.027 & 0.071 & 0.97 & 0.37 & 0.027 & 0.073 & 0.86 \\
\hline 854 & 0.54 & 0.032 & 0.059 & 0.98 & 0.44 & 0.025 & 0.056 & 0.96 & 0.39 & 0.028 & 0.072 & 0.95 \\
\hline 1003 & 0.56 & 0.037 & 0.066 & 0.93 & 0.45 & 0.024 & 0.053 & 0.88 & 0.40 & 0.026 & 0.065 & 0.83 \\
\hline 1679 & 0.58 & 0.038 & 0.066 & 0.90 & 0.5 & 0.013 & 0.026 & 0.87 & 0.42 & 0.033 & 0.079 & 0.81 \\
\hline 2204 & 0.48 & 0.039 & 0.081 & 0.91 & 0.42 & 0.030 & 0.071 & 0.89 & 0.32 & 0.034 & 0.106 & 0.88 \\
\hline
\end{tabular}

+ Mean (x), Standard Deviation (SD), Coefficient of Variation $(\mathrm{CV}=\mathrm{SD} / \mathrm{x})$

*Moran's I index expresses local spatial uniformity, ranges between +1 and $-1(+1=$ strong positive spatial autocorrelation,

$0=$ spatially uncorrelated data, $-1=$ strong negative spatial autocorrelation)

However, in the green and red region (550-700 $\mathrm{nm})$, reflectivity was highest at FMF (40-45, $\pm 2.5-2.8 \%)$, intermediate at IP (35-40, $\pm 2.4-2.8 \%)$, and lowest at RRVP (30-40, $\pm 2.5 \%)$. The same trend continued in the NIR (700-2000 nm): FMF $50-55 \%( \pm 3.1-7.2 \%)$, IP $42-48 \%( \pm 1.5-5 \%)$, and RRVP $37-40 \%( \pm 2.3-5.8 \%)$; and in the SWIR (2000-2450 nm): FMF $48-52 \%( \pm 3-18 \%)$, IP $40-48 \%( \pm 2-6.5 \%)$, and RRVP $32-45 \%( \pm 3-7.5 \%)$. The highest SDs were associated with artifacts due to imperfections in the atmospheric correction procedures for scattering in the blue region and for absorption by water vapor near absorption features at $930 \mathrm{~nm}, 1450 \mathrm{~nm}$ and $1950 \mathrm{~nm}$. In the $2360-2450 \mathrm{~nm}$ region, where the derived reflectance is less stable, due to lowered SNR of the instrument, the variation in the moisture content in the playa caused greater overall impact and the SD were consistently higher at all sites.

The temporal variation in the reflectance characteristics of the three PICS are represented by individual bands in the blue, green, red, NIR, and SWIR regions (means and SD, Fig. 2). While the magnitude of the reflectance differed per spectral band, all reflective regions exhibited relatively uniform and flat temporal profiles, devoid of consistent temporal trends (Fig. 2). Lower reflectance values (with higher SD) across all spectral bands occurred during winter months at FMF (DOY 12, 337) and RRVP (DOY 12, 288), which could be attributed to lower incoming radiation, higher shadow component, local illumination effects not accounted for in the atmospheric correction model, and/or increased soil moisture at these playas. Fig. 3(a), (b), (c) and Table IV summarize the long-term spectral reflectance responses at the three PICS. The statistics (x, SD, CV) summarize band responses across time (Fig. 3, Table IV).

The reflectance time series at the PICS were devoid of apparent spectral trends, allowing us to have sufficient confidence in the data to describe the temporal dynamics at the VFS sites.

\section{B. Seasonal Dynamics in Hyperion Reflectance Parameters and NEP at Validation FLUXNET Sites (VFS)}

Seasonal changes in Hyperion reflectance spectra over the forested Duke LP (Fig. 4(a)) and HW sites (Fig. 4(b)), the Konza prairie TG site (Fig. 4(c)), and the Mongu MW site (Fig. 4(d)) displayed typical vegetation reflectance trends: relatively low VIS reflectance due to high absorption by leaf photosynthetic pigments, with a peak $\sim 550 \mathrm{~nm}$, relatively bright NIR reflectance $(700-1300 \mathrm{~nm})$ because absorption is weak but scattering is strongly expressed by canopy structural components and the contrast between indices of refraction for water-rich cells and intercellular air spaces, and strong absorption in the SWIR (1450-2450 nm) by leaf water, cellulose, lignin, and other plant materials causing vegetation to appear relatively dark.

Hyperion's reflectance time series captured seasonal differences among the site-specific VFS carbon dynamics. Red reflectance wavelengths $(\sim 700 \mathrm{~nm})$ had the largest variation (large $\mathrm{CV}$ ) during the year at both the grassland and deciduous hardwood sites where $\mathrm{CV}>30 \%$ (HW, 50\%; TG, 47\%; and MW, 31\%), but CV was less variable at the pine stand (LP, $26 \%$ ). The largest spectral variations were observed in the blue and red VIS spectrum (Table V). For blue wavelengths $(450-500 \mathrm{~nm})$, there were no statistically significant differences among the seasonal spectra for any VFS, which is attributed to the very large $\mathrm{CV}(70 \%-128 \%)$ in this region, due to the lower S/N of Hyperion's first detector and imperfections in the correction for atmospheric scattering. Due to a pronounced wet/dry seasonality, the time series of red wavelengths at Mongu (Fig. 4) best tracked fluxes throughout the growing season.

Fig. 5 depicts the temporal profile of the continuum removal analyses for reflectances in the chlorophyll absorption features at each VFS. The normalized reflectances have values between 0 and 1 , enhancing the feature and allowing feature depths (FD, measured at $675 \mathrm{~nm}$ ) to be computed for temporal comparisons at each site, and among sites. At the Duke LP site, the FD did not vary significantly (during the year (mean FD $=0.81-0.84, \mathrm{p}>$ 0.25 ), while at the Duke HW site. FD dramatically changed from 0.23 (DOY 6) to 0.90 (DOY162). The FD also varied greatly throughout the year at the Konza TG site, from 0.81 (DOY 205) to 0.05 (DOY13) and at the Mongu MW from 0.83 (DOY 22) to 0.33 (DOY 253). At the Konza TG prairie site, the very low FDs $(0.05-0.16)$ can be explained by the dormancy and complete dieback of the above ground tallgrass biomass.

Attempts to analyze the dynamics in the SWIR absorption features (2220-2380 nm) associated with lignin, cellulose and 
(a)

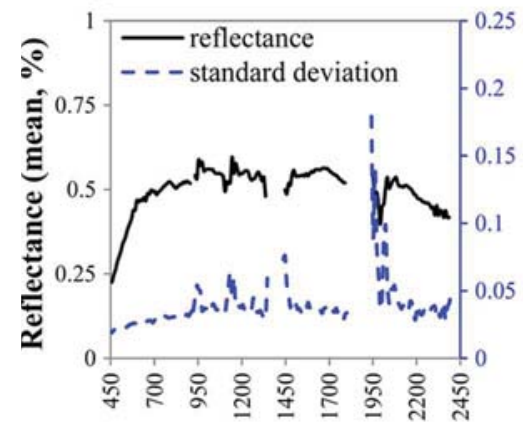

(b)

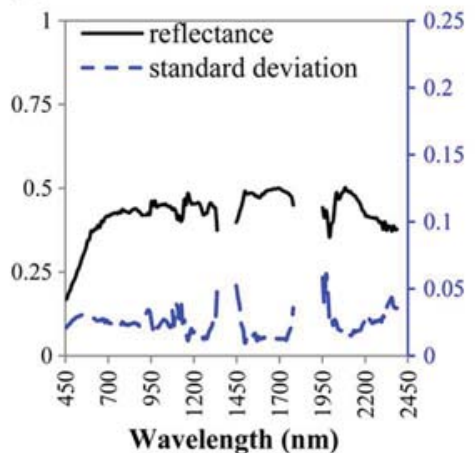

(c)

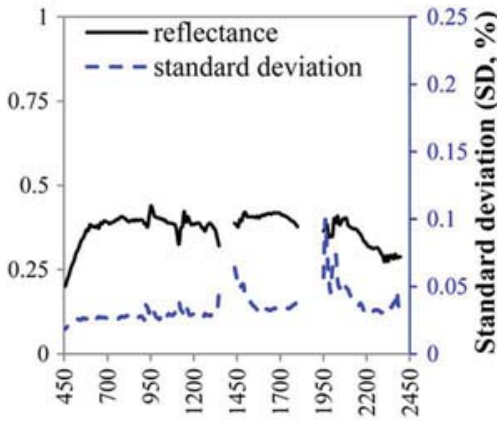

Fig. 3. Mean reflectance (\%, solid line) and standard deviation (\%, dashed line) for time series for: (a) Frenchman Flat (FMF, $\mathbf{n}=7$ ), (b) Ivanpah Playa (IP, $\mathrm{n}=6$ ), and (c) Railroad Valley Playa (RRVP, $\mathrm{n}=15$ ). Means and standard deviations are listed in Table IV.
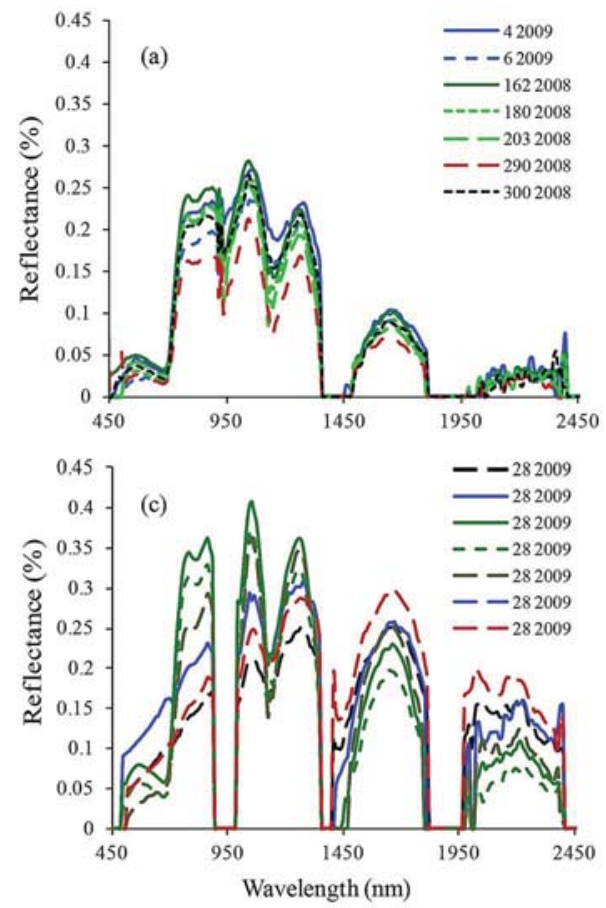
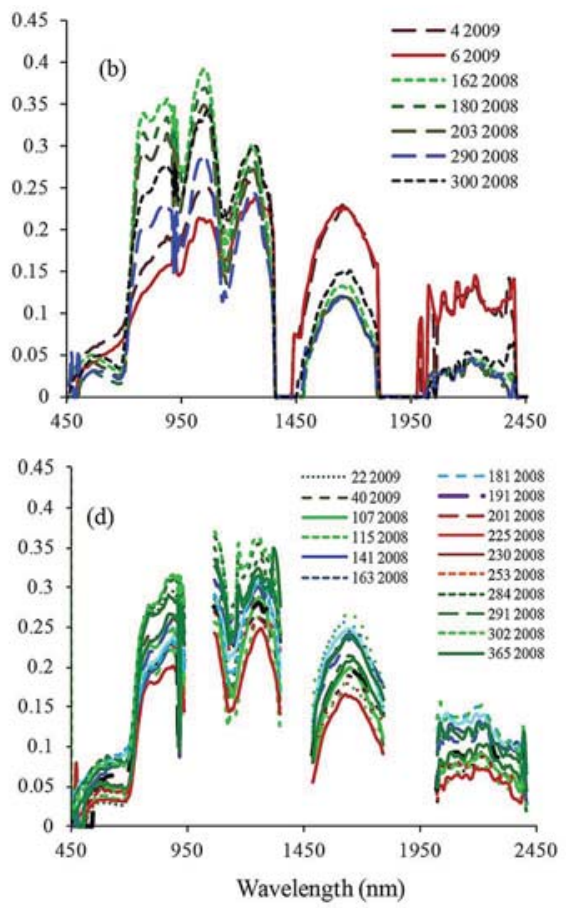

Fig. 4. Temporal variation in the Hyperion reflectance acquired over the validation sites: (a) Duke (loblolly pine, LP), (b) Duke (hardwoods, HW), (c) Konza (tallgrass, TG), and (d) Mongu (Miombo woodland, MW). Each line represents the mean site reflectance from a single day, designated in the labels as "DOY year".

nitrogen contents were not successful, due to low SNR which obscured the features and precluded the band depth analysis.

Hyperion narrowband VIs were calculated using continuous reflectance spectra or reflectance derivative (PRI1, PRI4, Dmax), and included wavelengths associated with chlorophyll content (e.g., PRI4, G94 and G32) and/or chlorophyll fluorescence (e.g. Dmax/D704, Dmax/D $(\max +12)$ ) (Tables VI, VII). Using a regression approach, we established that many of the VIs were closely related to NEP and GEP. The VIs with the strongest relationships to NEP and GEP are listed in Table VI, along with the simulated Landsat broadband VIs (e.g., NDVI, EVI) for comparison. The set of best performing VIs for estimating NEP varied among the sites. At the Duke LP site, the most successful narrowband VI for association with NEP was the DPI $\left(\mathrm{r}^{2}=0.91\right)$ a derivative index using three wavelengths, followed by linear relationships obtained with two variations of the photochemical reflectance index: PRI4 $\left(\mathrm{r}^{2}=0.85\right.$, Fig. 6(a)) and PRI1 $\left(\mathrm{r}^{2}=0.84\right)$. At the Duke HW site, the performance of PRI4 was non-linear but performed best $\left(\mathrm{r}^{2}=0.94\right.$, Fig. 6(a)), followed by Dmax $\left(\mathrm{r}^{2}=0.83\right)$. The PRI4 performed well at both LP and HW (Fig. 6(a)), however it saturated at values $\geq 0.2$, not being able to effectively discriminate for NEP $>20 \mu \mathrm{mol} \mathrm{m} \mathrm{m}^{-2} \mathrm{~s}^{-1}$.

At the TG Konza site, however, the most successful VIs for relating best to NEP were the narrowband G94 $\left(\mathrm{r}^{2}=0.95\right.$, Fig. 6(b), Table VI) and Dmax $\left(\mathrm{r}^{2}=0.93\right)$. G94 uses narrowband wavelengths in the NIR and red $\left(\mathrm{r}^{2}=0.95\right.$, Fig. 6(b) $)$ and it saturated at $\mathrm{G} 94>0.7$ for $\mathrm{NEP}>27 \mu \mathrm{mol} \mathrm{m}{ }^{-2} \mathrm{~s}^{-1}$. At the Mongu MW site, the most successful VIs for relating to NEP were G32 $\left(\mathrm{r}^{2}=0.83\right.$, Fig. 6(c)), Dmax/D704 $\left(r^{2}=0.79\right)$, and Dmax $\left(r^{2}=0.77\right)$. G32 combines wavelengths from the blue, red and NIR regions (Fig. 6(c)). At values of G32<0.3 this parameter saturated for $\mathrm{NEP}<5 \mu \mathrm{mol} \mathrm{m} \mathrm{m}^{-2} \mathrm{~s}^{-1}$. 
TABLE V

Seasonal Values for of Hyperion Reflectance at Validation FLUXNET Sites (VFS)

\begin{tabular}{|c|ccccc|cccc|ccc|}
\hline \multirow{4}{*}{$\begin{array}{c}\text { Wavelength } \\
(\mathrm{nm})\end{array}$} & \multicolumn{4}{|c|}{ Duke, NC, USA } & \multicolumn{3}{c|}{ Konza, KS, USA } & \multicolumn{4}{c|}{ Mongu, Zambia } \\
\cline { 2 - 12 } & \multicolumn{4}{|c|}{ Loblolly pine (LP) } & \multicolumn{1}{c|}{ Hardwoods (HW) } & \multicolumn{2}{c|}{ Tall Grassland (TG) } & \multicolumn{3}{c|}{ Miombo Woodland (MW) } \\
\cline { 2 - 12 }$y$ & Mean & St. Dev & CV & Mean & St. Dev & CV & Mean & St. Dev & CV & Mean & St. Dev & CV \\
\hline 447 & $0.018 n s$ & 0.019 & 1.11 & $0.011 n s$ & 0.008 & 0.72 & $0.035 n s$ & 0.044 & 1.27 & $0.013 n s$ & 0.017 & 1.28 \\
549 & $0.035 \dagger$ & 0.010 & 0.29 & 0.041 & 0.010 & 0.25 & 0.060 & 0.024 & 0.40 & 0.054 & 0.015 & 0.27 \\
651 & 0.026 & 0.007 & 0.26 & 0.039 & 0.019 & 0.50 & 0.073 & 0.035 & 0.48 & 0.060 & 0.019 & 0.32 \\
854 & 0.215 & 0.026 & 0.12 & 0.259 & 0.076 & 0.29 & 0.275 & 0.076 & 0.28 & 0.238 & 0.030 & 0.13 \\
1104 & 0.189 & 0.031 & 0.16 & 0.232 & 0.038 & 0.16 & 0.253 & 0.033 & 0.13 & 0.253 & 0.034 & 0.13 \\
1679 & 0.086 & 0.011 & 0.13 & 0.155 & 0.048 & 0.31 & 0.238 & 0.037 & 0.16 & 0.206 & 0.029 & 0.14 \\
2204 & 0.025 & 0.006 & 0.26 & 0.070 & 0.041 & 0.59 & 0.128 & 0.041 & 0.32 & 0.108 & 0.023 & 0.21 \\
\hline
\end{tabular}

ns - no statistically significant differences among means by day of year (based on ANOVA)

${ }^{\dagger}$ when not noted as ns, there were statistically significant differences among means by day of year at $\mathrm{p}<0.05$ level

(a) LP (Duke, NC, USA)

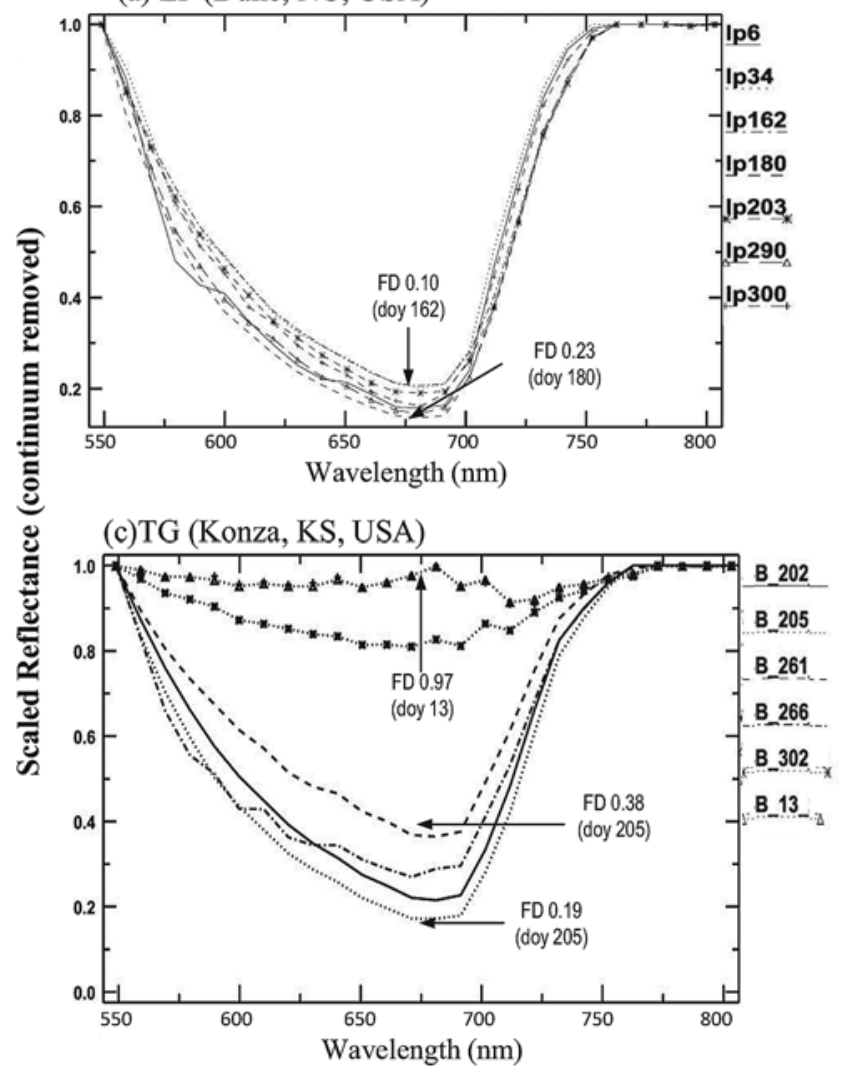

(b) HW (Duke NC, USA)

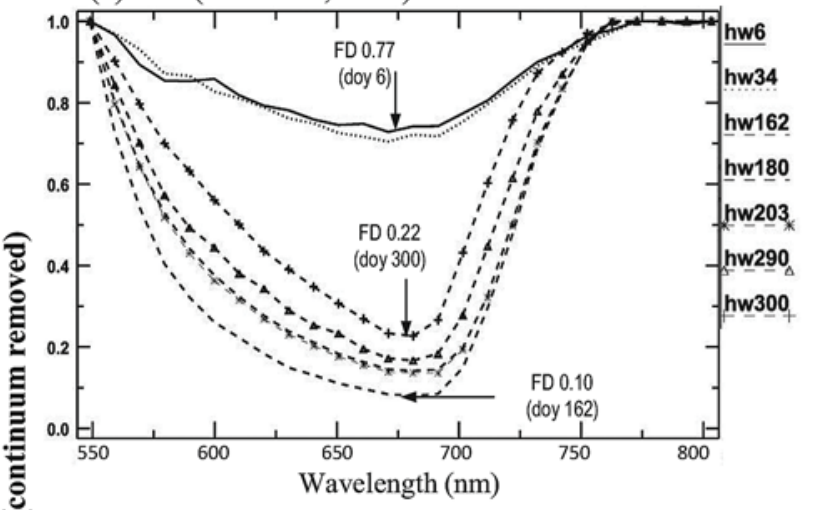

(d) MW (Mongu, Zambia)

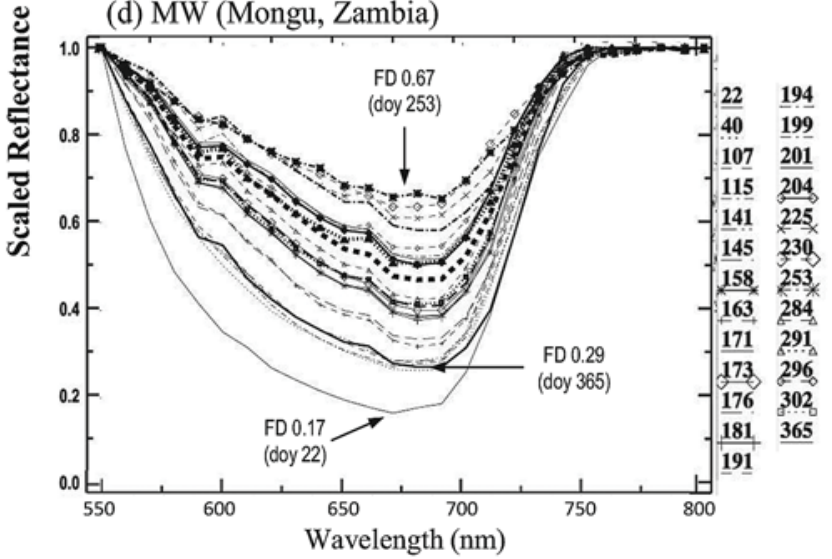

Fig. 5. Temporal variation in the mean normalized reflectance (continuum removed) from the chlorophyll absorption feature, (550-750 nm) illustrating the spectral dynamics at each validation site by DOY: (a) Duke LP ( $\mathrm{n}=6$ days), (b) Duke HW ( $\mathrm{n}=6$ days), (c) Konza TG ( $\mathrm{n}=6$ days, each line is an average of spectra from areas under 1 and 4 year burn), and (d) Mongu MW ( $\mathrm{n}=15$ days).

At all VFSs, the VIs best related to NEP were also strongly related to GEP, with strongest relationship for the Konza TG site (Table VI). The broadband EVI also performed well at the Duke HW site $\left(\mathrm{NEP}, \mathrm{r}^{2}=0.84\right)$, Konza TG site $\left(\mathrm{NEP}, \mathrm{r}^{2}=0.83\right.$; GEP, $\left.r^{2}=0.89\right)$ and at the Mongu MW site (NEP, $\mathrm{r}^{2}=0.73$; GEP, $\left.\mathrm{r}^{2}=0.88\right)$. Fig. 7 depicts the best performing VIs for NEP across all sites. Most of these relationships were curvilinear (Fig. 6, Table VI). Hyperion narrowband VIs with the stronger relationship to $\mathrm{CO}_{2}$ parameters (Tables VI and VII) were calculated using continuous reflectance spectra or reflectance derivative (e.g. PRI1, PRI4, Dmax), and included wavelengths associ- ated with chlorophyll content (e.g., PRI4, G94 and G32) and/or chlorophyll fluorescence (e.g. DPI, Dmax/D704).

To assess the potential of using a common high resolution VI for tracking $\mathrm{CO}_{2}$ seasonal dynamics across multiple sites and ecosystems, we combined the data from all VFS $(n=52$, Table VII, and Fig. 8). The derivative parameters Dmax (associated with vegetation stress) and DP22 (associated with chlorophyll fluorescence) exhibited a strong relationships to NEP and GEP $\left(\mathrm{r}^{2}=0.65-0.73\right.$ and $\mathrm{r}^{2}=0.74-77$, respectively), as did the normalized difference water index (NDWI, $\mathrm{r}^{2}=0.74$ to NEP and $\mathrm{r}^{2}=0.67$ to GEP, Table VII). These 
TABLE VI

Hyperion Vegetation Indices (VIs) Having Strongest Relationships $\left(\mathrm{r}^{2}\right)$ to $\mathrm{CO}_{2}$ Uptake Parameters (NEP and GEP), By Study Site. Hyperion's Best Performing High Spectral Resolution VIs are Listed First. The Broadband Landsat Parameters are Listed for Comparison in Italics

\begin{tabular}{|c|c|c|c|c|}
\hline Index & Bands (nm) & $\mathbf{r}^{2}$ to NEP & $r^{2}$ to GEP & $\mathbf{L} / \mathrm{NL}^{*}$ \\
\hline \multicolumn{5}{|c|}{ a. Loblolly Pine (LP), Duke, NC $(n=7)$} \\
\hline DPI & $(\mathrm{D} 688 * \mathrm{D} 710) /(\mathrm{D} 697 * \mathrm{D} 697)$ & $\mathbf{0 . 9 1} ; \mathrm{p}<0.01$ & $0.44, \mathrm{~ns}$ & NL \\
\hline PRI1 & (R531-R570)/(R531-R570) & 0.84; $\mathrm{p}<0.01$ & $0.73 ; \mathrm{p}<0.01$ & $\mathbf{L}$ \\
\hline PRI4 & (R531-R670)/(R531-R670) & $\mathbf{0 . 8 5} ; \mathrm{p}<0.01$ & $0.63 ; \mathrm{p}<0.05$ & $\mathrm{~L}$ \\
\hline NDWI & $(\mathrm{R} 870-\mathrm{R} 1240) /(\mathrm{R} 870+\mathrm{R} 1240)$ & $0.76 ; \mathrm{p}<0.05$ & $0.60, \mathrm{~ns}$ & $\mathrm{~L}$ \\
\hline$N D V I_{\text {Landsat }}$ & $(N I R-R E D) /(N I R+R E D * *$ & $0.19, n s$ & $0.48, n s$ & $L$ \\
\hline \multicolumn{5}{|c|}{ b. Hardwoods (HW), Duke, NC (n=7) } \\
\hline PRI4 & (R531-R670)/(R531-R670) & $0.95 ; \mathrm{p}<0.01$ & $0.48, \mathrm{~ns}$ & NL \\
\hline Dmax & Dmax $=$ Highest $\mathrm{I}^{\mathrm{st}}$ Derivative, $650-750 \mathrm{~nm}$ & $0.83 ; \mathrm{p}<0.01$ & $0.40, \mathrm{~ns}$ & NL \\
\hline NDII & $(\mathrm{R} 820-\mathrm{R} 1650) /(\mathrm{R} 820+\mathrm{R} 1650)$ & $0.79 ; \mathrm{p}<0.01$ & $0.34, \mathrm{~ns}$ & $\mathrm{~L}$ \\
\hline EVI Landsat & $2.5(N I R-R E D) /(N I R+6 R E D-7.5 B L U E+1)^{* *}$ & $0.84 p<0.01$ & $0.41, n s$ & $L$ \\
\hline$N D V I_{\text {Landsat }}$ & $(N I R-R e d) /(N I R+R E D)$ & $0.63 ; \mathrm{p}<0.05$ & $0.19, n s$ & $L$ \\
\hline \multicolumn{5}{|c|}{ c. Tall Grassland (TG), Konza, KS ( $\mathrm{n}=14$, combining $1 \& 4$ year burn) } \\
\hline G94 & $(\mathrm{R} 800-\mathrm{R} 700) /(\mathrm{R} 800+\mathrm{R} 700)$ & $0.95 ; \mathrm{p}<0.01$ & $0.90 ; \mathrm{p}<0.01$ & NL \\
\hline Dmax & Maximum of the $\mathrm{I}^{\mathrm{st}}$ Derivative in $650-750 \mathrm{~nm}$ & $\underline{0.93 ;} \mathrm{p}<0.01$ & 0.95; $\mathrm{p}<0.01$ & $\mathrm{~L}$ \\
\hline NDWI & $(\mathrm{R} 870-\mathrm{R} 1240) /(\mathrm{R} 870+\mathrm{R} 1240)$ & $0.86 ; \mathrm{p}<0.01$ & $0.91 ; \mathrm{p}<0.01$ & NL \\
\hline EVI Landsat & $2.5($ RNIR-Rred $) /(\text { RNIR+6Rred-7.5Rblue }+1)^{* *}$ & $0.83 ; p<0.01$ & $0.89 ; p<0.01$ & $N L$ \\
\hline$N D V I_{\text {Landsat }}$ & $(N I R-R e d) /(N I R+R E D)$ & $0.63, n s$ & $0.67 ; \mathrm{p}<0.05$ & $L$ \\
\hline \multicolumn{5}{|c|}{ d. Miombo Woodland (MW), Mongu, Zambia $(n=24)$} \\
\hline G32 & $\mathrm{R} 750,700,450$ & $0.83 ; \mathrm{p}<0.01$ & $0.81 ; \mathrm{p}<0.01$ & NL \\
\hline Dmax & Maximum of the $\mathrm{I}^{\mathrm{st}}$ Derivative in $650-750 \mathrm{~nm}$ & $0.77 ; \mathrm{p}<0.01$ & $0.87 ; \mathrm{p}<0.01$ & NL \\
\hline Dmax/D704 & Dmax/D704 & $0.79 ; \mathrm{p}<0.01$ & $0.80 ; \mathrm{p}<0.01$ & NL \\
\hline EVI Landsat & $2.5($ RNIR-Rred $) /($ RNIR +6 Rred -7.5 Rblue +1$)$ & $0.73 ; p<0.0$ & $0.88 ; p<0.01$ & $L$ \\
\hline$N D V I_{\text {Landsat }}$ & $($ NIR-Red) $/(N I R+R E D)$ & $0.52, n s$ & $0.60 ; \mathrm{p}<0.05$ & $N L$ \\
\hline
\end{tabular}

${ }^{*} \mathrm{NEP}$ (net ecosystem production), GEP (gross ecosystem production), L (linear relation), NL (non-linear regression)

** NIR (average R760-900 nm), Red (average R620-690 nm), Blue (average R450-500 nm), after the Landsat bands

results illustrate the possibility for establishing a common spectral approach based on high resolution VIs for tracking $\mathrm{CO}_{2}$ ecosystem dynamics. Dmax was able to provide separation for most of the data, but it saturated at Dmax $>0.65$ for NEP $>25 \mu \mathrm{mol} \mathrm{m}^{-2} \mathrm{~s}^{-1}$ (Fig. 8). The use of derivatives, reducing the effects of variable irradiance, canopy structure and bidirectional properties, offers an important potential when analyzing reflectance time series.

It is important to note that the Landsat broadband VIs never performed as well as the narrow-band indices. At the HW, TG and MW sites EVI performed almost as well as the "optimal" narrow-band VIs, but not at the LP site (Table VI) or when analyzing the combined data set (Table VII).

\section{Discussion}

We were able to evaluate Hyperion reflectance stability over the full instrument spectrum and large portion of the EO-1 life- time, for which there was available data. Since the collection of sufficient number of free of clouds images to generate the time series took multiple years, we constructed a seasonal time line by arranging the data consecutively by acquisition day from any given year.

Our results from the three PICS demonstrate the spectral stability of Hyperion's reflectance time series, and provide spatial uniformity descriptors at each of these well-known sites where the time series have been collected. This spectral stability verifies the potential of Hyperion's reflectance time series for ecosystem monitoring. As new images are added to the seasonal time lines, the ability of the reflectance time series to assess vegetation function will likely improve. Future work is required to refine the atmospheric correction process and to improve the reflectance estimates in spectral regions with lower stability (e.g. $2000-2450 \mathrm{~nm}$ region, and near water absorption bands). Further improvements in the atmospheric correction approach, the 
TABLE VII

Spectral Bio-Indicators of Vegetation Function With Best Correlation to $\mathrm{CO}_{2}$ Uptake for Multiple Sites (Combined Data Set From THE THREE VFS, $\mathrm{n}=52$ )

\begin{tabular}{|c|c|c|c|}
\hline $\begin{array}{l}\text { Spectral } \\
\text { indicator }\end{array}$ & Formula & $r^{2}$ to $\operatorname{NEP}^{\dagger}(\mathrm{L} / \mathrm{NL})^{*}$ & $r^{2}$ to GEP $\$(L / N L)$ \\
\hline Dmax & Highest I $\mathrm{It}^{\mathrm{st}}$ Derivative, $650-750 \mathrm{~nm}$ & $0.73, \mathrm{p}<0.01(\mathrm{~L})$ & $\underline{0.77}, \mathrm{p}<0.01(\mathrm{~L})$ \\
\hline DP22 & $\operatorname{Dmax} / \mathrm{D}_{(\max +12)}$ & $0.65, \mathrm{p}<0.01(\mathrm{~L})$ & $0.74, \mathrm{p}<0.01(\mathrm{NL})$ \\
\hline NDWI & $\mathrm{R}(870-1240) / \mathrm{R}(870-1240)$ & $\underline{0.74}, \mathrm{p}<0.01(\mathrm{NL})$ & $0.67, \mathrm{p}<0.01,(\mathrm{NL})$ \\
\hline MCARIa & $\left.[(\mathrm{R} 700-\mathrm{R} 675)-(0.2 *(\mathrm{R} 700-\mathrm{R} 550)))^{*} \mathrm{R}(700 / \mathrm{R} 675)\right]$ & $0.41, \mathrm{p}<0.01(\mathrm{~L})$ & $0.75, \mathrm{p}<0.01(\mathrm{~L})$ \\
\hline PRI4 & (R531-R670)/(R531-R670) & $0.66, \mathrm{p}<0.01(\mathrm{NL})$ & $0.62, \mathrm{p}<0.05(\mathrm{NL})$ \\
\hline$N D V I_{\text {Landsat }}$ & $(N I R-R) /(N I R+R)^{* *}$ & $0.56, n s(N L)$ & $0.59, n s(N L)$ \\
\hline
\end{tabular}

${ }^{\dagger} \mathrm{NEP}$ (net ecosystem production)

${ }^{\ddagger} \mathrm{GEP}$ (gross ecosystem production)

${ }^{*} \mathrm{~L}$ (linear relation), NL (non-linear relation)

** NIR (average R760-900 nm), Red (average R620-690 nm), Blue (average R450-500 nm), after the Landsat bands

(a) Duke ( $\mathrm{n}=14), \mathrm{LP}(\mathrm{n}=7)$ and HW ( $=7$ )

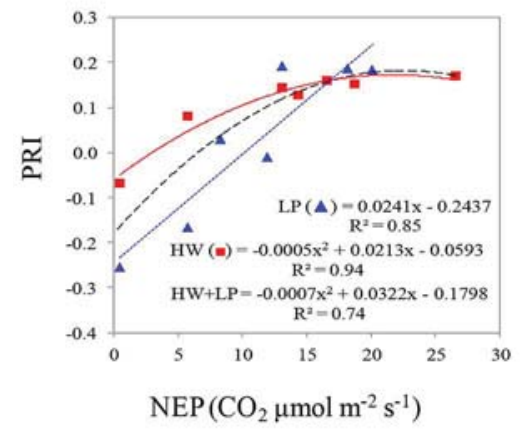

(b) TG, Konza (n=14)

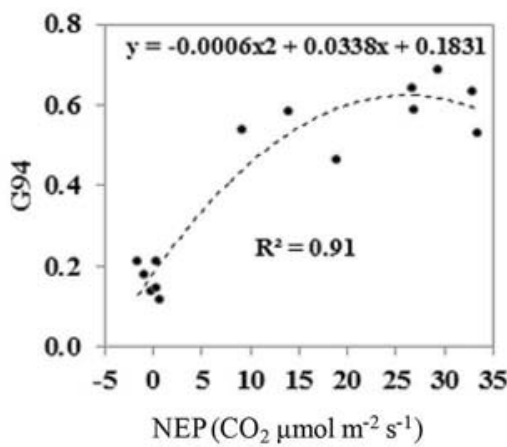

(c) MW, Mongu ( $\mathrm{n}=24)$

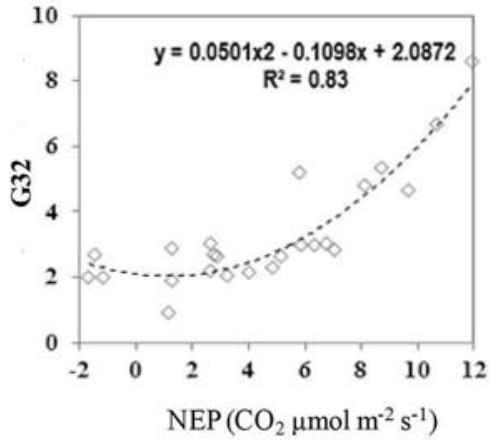

Fig. 6. Relationship of Hyperion's best performing VIs in relation to NEP at each study site $(\mathrm{p}<0.01)$. At Duke (Fig. $6(\mathrm{a}))$, the photochemical reflectance index PRI4 using green and red wavelengths $\left(\mathrm{PRI} 4=(\mathrm{R} 531-\mathrm{R} 670) /(\mathrm{R} 531-\mathrm{R} 670)\right.$, performed well at both LP $\left(\mathrm{r}^{2}=0.85\right)$ and HW $\left(\mathrm{r}^{2}=0.94\right)$ forests. However, the index saturated at PRI4 $\sim 0.2$, not being able to effectively discriminate NEP $>20 \mu \mathrm{mol} \mathrm{m}^{-2} \mathrm{~s}^{-1}$. At the TG Konza site, the most successful VI was narrowband G94 $\left(\mathrm{r}^{2}=0.95\right.$, Fig. 6(b); G94 $\left.=(\mathrm{R} 800-\mathrm{R} 700) /(\mathrm{R} 800+\mathrm{R} 700)\right)$, which saturated at G94 $\sim 0.7$, not being able to separate $\mathrm{NEP}>27 \mu \mathrm{mol} \mathrm{m}{ }^{-2} \mathrm{~s}^{-1}$. At the Mongu MW site, the most successful VI was G32 ( $\mathrm{r}^{2}=0.83$, Fig. $\left.6(\mathrm{c}), \mathrm{G} 32=(\mathrm{R} 750-\mathrm{R} 445) /(\mathrm{R} 700-\mathrm{R} 445)\right)$ combining wavelengths from the blue, red and NIR regions. At low values of G32 $<0.3$ this parameter saturated, not allowing separation of NEP $<5 \mu \mathrm{mol} \mathrm{m} \mathrm{m}^{-2} \mathrm{~s}^{-1}$.

incorporation of topographic information, and additional calibration of Hyperion reflectances to targeted in situ field spectral measurements, are required to expand the number of useful reflectance bands at VFS. These improvements are especially needed in the 850 to $2500 \mathrm{~nm}$ range where they may allow better reflectance retrieval and thus, narrow-band VIs using bands in these ranges may be better correlated to NEP and GEP than in the current analysis.

Hyperion's long-term reflectance measurements offer the potential for cross-comparison with other optical sensors. Cross-calibration of current multispectral sensors to hyperspectral instruments such as Hyperion, could serve for inter-comparisons and retroactive data processing. Currently there is a consistent NDVI record that extends more than 2 decades, generated from the Advanced Very High Resolution Radiometer (AVHRR) instruments, which provides a historical perspective on vegetation dynamics necessary for global change research. Long term spectral records are also available from SPOT-Vegetation, SeaWiFS, Moderate Resolution Imaging Spectroradiometer, Landsat ETM+ data and others.
While the spectral vegetation indices (VIs) are considered more directly transferable between sensors, and an intercalibrated, sensor-independent NDVI data record could be feasible, there are significant challenges and higher discrepancies associated with the inter-comparison of biophysical products, which are generated using different instruments with varying spectral and spatial resolution, modeling approaches and ground data [50]-[52].

Simultaneous calibration of old and new sensors against each other over a common set of targets on the Earth is a key requirement for maintaining long-term records (http://wgcv.ceos. org/). Our results indicate that the use of space-borne spectrometers allow assessment of the spectral stability and spatial variability of the calibration sites. The reflectance measurements at the PICS confirm that they meet the CEOS/WGCV surface reflectance requirement for above $30 \%$ reflectivity and flat spectral signature over the $600-2000 \mathrm{~nm}$ range.

In recent years, a growing number of studies have recognized the importance of collecting spectroscopy observations at flux towers to better understand the relationship between vegeta- 
(a)

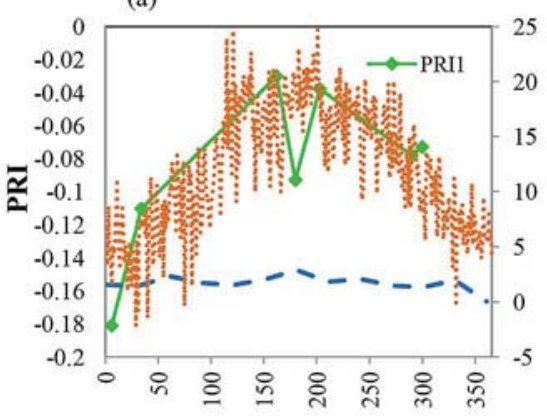

(b)

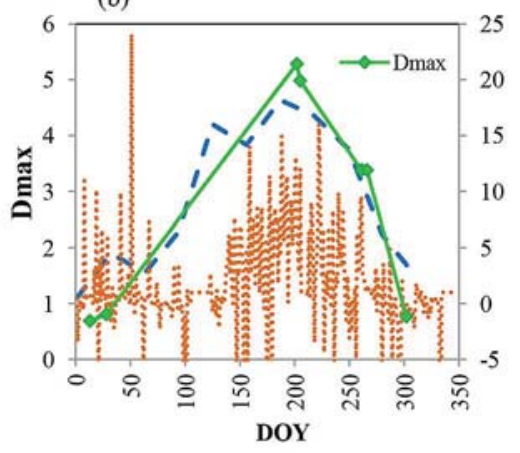

(c)

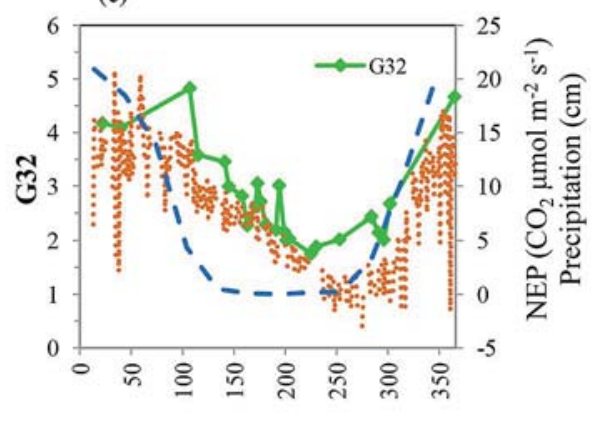

Fig. 7. Temporal variation in the best performing spectral indices for Konza, Duke (LP), Mongu (reflectance means (x) by DOY). Dotted line is NEP while dashed line is precipitation.

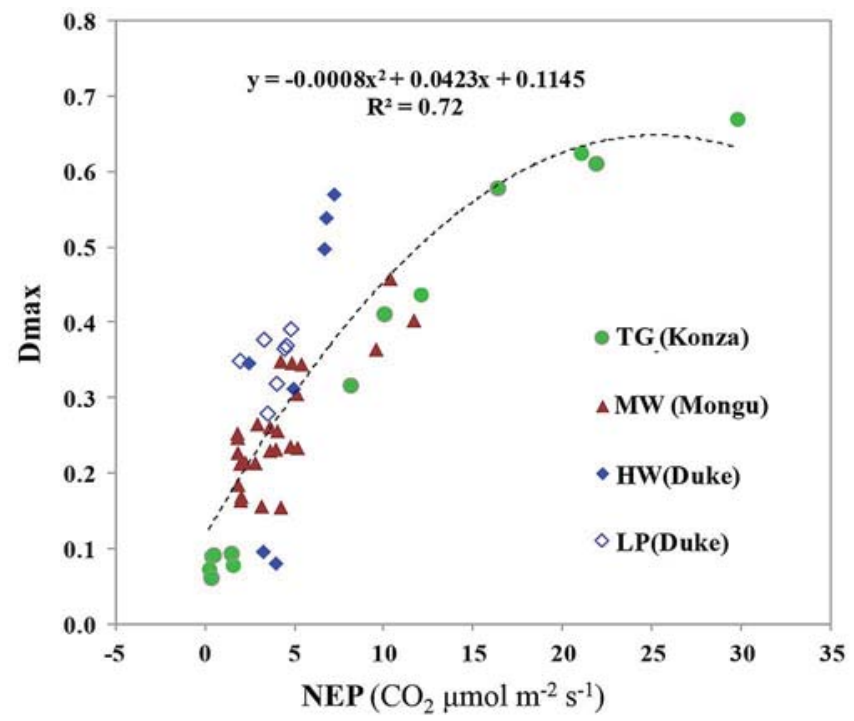

Fig. 8. Relationship of Hyperion's derivative index Dmax (the maximum amount of the first derivative in the $650-750 \mathrm{~nm}$ region) to the $\mathrm{CO}_{2}$ assimilation (NEP, $\mu \mathrm{mol} \mathrm{m} \mathrm{m}^{-2} \mathrm{~s}^{-1}$ ) across the three VFS. Dmax had closest relationship when using the combined data set $(\mathrm{n}=52, \mathrm{p}<0.01)$. However this parameter saturated at Dmax $>0.65$, precluding the separation of $\mathrm{NEP}>20 \mu \mathrm{mol} \mathrm{m}^{-2} \mathrm{~s}^{-1}$.

tion function and optical signals [53]. Our results at the three VFSs demonstrate the close link between Hyperion's VIs and carbon flux measurements and the potential for scaling the tower measurements to local, regional and potentially global levels. Multiple observations at individual sites are required to test the ability of the VIs to describe seasonal and transient variations in fluxes. It is noteworthy that the VIs with stronger relationships to the $\mathrm{CO}_{2}$ parameters were derived using continuous reflectance spectra or reflectance derivatives, and included wavelengths associated with chlorophyll content and/or chlorophyll fluorescence (e.g. DPI, Dmax/D704 and PRI). Since these indices cannot be calculated from broadband multispectral instrument data, the opportunity to exploit these spectrometer-based VIs in the future will depend on the launch of satellites such as En MAP and HyspIRI.

Space borne spectrometers offer potential for establishing a generalized approach for scaling $\mathrm{CO}_{2}$ dynamics across multiple sites and to local and regional levels. Site-specific equations provided more accurate results than the multisite groupings, although the trade-offs between the improved accuracy of a site-specific algorithm versus an algorithm for general use have yet been established. The development of common (i.e. global) spectral approaches to track vegetation function and scale up carbon estimates requires diverse spectral data sets, comprised of the major ecosystem types in a broad range in functional states.

The performance of narrow-band VIs from satellite time series remains to be thoroughly examined for various vegetation types exhibiting a range of local conditions. Future work will expand the analysis by extending the time series at our study sites as well as adding additional sites representing other ecosystem types, including rain forest, temperate and sub-arctic vegetation. Testing algorithms over longer time series and more diverse cases will increase our ability to determine fluxes with higher confidence. Using hyperspectral data operationally will allow us to develop new more dynamic and accurate approaches to predict ecosystem parameters.

\section{CONCLusions}

With over 11 years of data record including more than 65,000 globally distributed hyperspectral images collected to date (as of July 20 2012), the Hyperion data record provides an important and unique resource for various Earth observations. This study provides a step towards better understanding and broader use of the Hyperion reflectance time series for monitoring of vegetation function and ecosystem dynamics. Hyperion reflectance measurements were shown to be stable over time in all spectral regions. The most stable portion of the spectrum was the visible and near infrared region, providing higher confidence for common use of chlorophyll based VIs. In three different ecosystems, Hyperion's VIs were found to be correlated with $\mathrm{CO}_{2}$ flux parameters. The VIs with the strongest relationships required continuous spectra, or numerous wavelengths associated with chlorophyll content and/or first derivative parameters, which are not available from broad-band multispectral instruments. This study showed their use with Hyperion's time series, demonstrating their close relationship to ecosystem carbon dynamics and potential for improved monitoring of carbon fluxes. 


\section{ACKNOWLEDGMENT}

Flux tower data for this study was provided by Dr. Brunsell (KNZ-LTER) for the Konza Prairie site, by Dr. Kimberly Novick (The School of the Environment at Duke University) for the Duke Forest sites, and by CarboAfrica (http://www.carboafrica.net/, PI for Mongu Dr. W. Kutsch). The authors warmly acknowledge their support and collaboration.

\section{REFERENCES}

[1] E. M. Middleton, D. J. Mandl, P. K. Campbell, L. Ong, S. W. Frye, and S. G. Ungar, "A ten year summary of NASA's Earth Observing One (EO-1) mission," in ESA Hyperspectral Workshop, 17-19 March 2010, Frascati, Italy. Proceedings SP-683, May 2010.

[2] B. Datt, T. R. McVicar, T. G. Van Niel, and J. S. Pearlman, "Preprocessing EO-1 hyperion hyperspectral data to support the application of agricultural indexes," IEEE Trans. Geosci. Remote Sens., vol. 41, no. 2, pp. 1246-1259, 2003.

[3] P. A. Townsend and J. R. Foster, "Comparison of EO-1 Hyperion to AVIRIS for mapping forest composition in the Appalachian mountains, USA," in IEEE Int. Geoscience and Remote Sensing Symp., 2002, vol. 2, no. 24-28, pp. 793-795.

[4] D. A. Roberts, K. L. Roth, and R. L. Perroy, "Hyperspectral Vegetation Indices," in Hyperspectral Remote Sensing of Vegetation, P. S. Thenkabail, J. G. Lyon, and A. Huete, Eds. New York: Taylor and Francis, 2011, ch. 14

[5] M. E. Martin, L. C. Plourde, S. V. Ollinger, M.-L. Smith, and B. E. McNeil, "A generalizable method for remote sensing of canopy nitrogen across a wide range of forest ecosystems," Remote Sens. Environ., vol. 112, no. 9, pp. 3511-3519, 2008.

[6] S. V. Ollinger, A. D. Richardson, M. E. Martin, D. Y. Hollinger, S. E. Frolking, P. B. Reich, L. C. Plourde, G. G. Katul, J. W. Munger, R. Oren, M.-L. Smith, K. T. Paw Ug, P. V. Bolstad, B. D. Cook, M. C. Day, T. A. Martin, R. K. Monson, and H. P. Schmid, "Canopy nitrogen, carbon assimilation, and albedo in temperate and boreal forests: Functional relations and potential climate feedbacks," Proc. National Academy of Sciences, vol. 105, no. 49, 2008.

[7] Y.Zeng, M. E. Schaepman, B. Wu, J. G. P. W. Clevers, and A. K. Bregt, "Forest structural variables retrieval using EO-1 Hyperion data in combination with linear spectral unmixing and an inverted geometric-optical model," J. Remote Sens., Special Issue on ISPMSRS05, vol. 11, no. 5, 2008.

[8] J. P. Guerschman, M. J. Hill, L. J. Renzullo, D. J. Barrett, A. S. Marks, and E. J. Botha, "Estimating fractional cover of photosynthetic vegetation, non-photosynthetic vegetation and bare soil in the Australian tropical savanna region upscaling the EO-1 Hyperion and MODIS sensors," Remote Sens. Environ., 2009.

[9] G. P. Asner, "Hyperspectral remote sensing of canopy chemistry, physiology and diversity in tropical rainforests," in Hyperspectral Remote Sensing of Tropical and Subtropical Forests, M. Kalacska and G. A. Sanchez-Azofeifa, Eds. New York: Taylor and Francis, 2008, ch. 12.

[10] K. J. Thome, S. F. Biggar, and W. T. Wisniewski, "Cross-comparison of EO-1 sensors and other earth resources sensors to Landsat-7 ETM+ using Railroad Valley Playa," IEEE Trans. Geosci. Remote Sens., vol. 41, pp. 1180-1188, 2003.

[11] S. F. Biggar, K. J. Thome, and W. T. Wisniewski, "Vicarious radiometric calibration of EO-1 sensors by reference to high-reflectance ground targets," IEEE Trans. Geosci. Remote Sens., vol. 41, pp. 1174-1179, 2003.

[12] K. J. Thome, J. Czapla-Myers, and S. Biggar, ESA/IVOS05, "Railroad Valley Playa for use in vicarious calibration of large footprint sensors," in IVOS Workshops, 2009, vol. 29.

[13] R. O. Green, B. E. Pavri, and T. G. Chrien, "On-orbit radiometric and spectral calibration characteristics of EO-1 Hyperion derived with an underflight of AVIRIS and in situ measurements at Salar de Arizaro, Argentina," IEEE Trans. Geosci. Remote Sens., 2003.

[14] G. P. Asner and K. B. Heidebrecht, "Imaging spectroscopy for desertification studies: Comparing AVIRIS and EO-1 Hyperion in Argentina drylands," IEEE Trans. Geosci. Remote Sens., vol. 41, no. 6, pp. 135-155, 2003.
[15] L. S. Galvão, J. R. dos Santos, D. A. Roberts, F. M. Breunig, M. Toomey, and Y. M. de Moura, "On intra-annual EVI variability in the dry season of tropical forest: A case study with MODIS and hyperspectral data," Remote Sens. Environ., vol. 115, no. 9, pp. 2350-2359, 2011.

[16] B.-C. Gao, M. J. Montes, C. O. Davis, and A. F. H. Goetz, "Atmospheric correction algorithms for hyperspectral remote sensing data of land and ocean," Remote Sens. Environ., vol. 113, pp. S17-S24, 2009, (Supplement 1).

[17] H. G. Jones and R. A. Vaughan, Remote Sensing of Vegetation: Principles, Techniques and Applications. New York: Oxford University Press, 2010, ISBN 978-0-19-920779-4.

[18] S. V. Ollinger, "Sources of variability in canopy reflectance and the convergent properties of plants," New Phytologist, vol. 189, pp. 375-394, 2011.

[19] P. J. Zarco-Tejada, J. Pushnik, S. Dobrowski, and S. L. Ustin, "Steadystate chlorophyll-a Fluorescence detection from canopy derivative reflectance and Double-Peak Red-Edge effects," Remote Sens. Environ., vol. 84, no. 2, pp. 283-294, 2003.

[20] P. K. E. Campbell, E. M. Middleton, L. A. Corp, J. E. McMurtrey III, and E. W. Chappelle, "Comparison of foliar fluorescence and reflectance measurements for the detection of vegetation stress," J. Environ. Quality, vol. 36, pp. 832-845, 2007.

[21] A. A. Gitelson, "Nondestructive estimation of foliar pigment (chlorophylls, carotenoids, and anthocyanins) contents: Evaluating a semianalytical three-band model," in Hyperspectral Remote Sensing of Vegetation, P. S. Thenkabail, J. G. Lyon, and A. Huete, Eds. New York: Taylor and Francis, 2011.

[22] P. M. Teillet, J. A. Barsi, G. Chander, and K. J. Thome, "Prime candidate earth targets for the post-launch radiometric calibration of spacebased optical imaging instruments," in Proc. SPIE Conf. 6677 on Earth Observing Systems, vol. XII (2007) Society of Photo-optical Instrumentation Engineers, San Diego, CA.

[23] H. N. Gross and S. L. Green, "Experimental determination of bi-directional reflectance distribution at the LSpec vicarious calibration site," in Algorithms and Technologies for Multispectral, Hyperspectral, and Ultraspectral Imagery XV, Proc. SPIE 7334, S. S. Shen and P. E. Lewis, Eds., 2009, pp. 733412-733421, 10.1117/12.818488.

[24] B. N. Holben, T. F. Eck, I. Slutsker, D. Tanre, J. P. Buis, A. Setzer, E. Vermote, J. A. Reagan, Y. Kaufman, T. Nakajima, F. Lavenu, I. Jankowiak, and A. Smirnov, "AERONET-A federated instrument network and data archive for aerosol characterization," Remote Sens. Environ., vol. 66, pp. 1-16, 1998.

[25] K. P. Scott, K. J. Thome, and M. R. Brownlee, "Evaluation of the Railroad Valley Playa for use in vicarious calibration," Proc. SPIE 2818, pp. 158-166, 1996.

[26] J. Czapla-Myers, K. Thome, and N. Leisso, "Radiometric calibration of earth-observing sensors using an automated test site at Railroad Valley, Nevada," Can. J. Remote Sens., vol. 36, no. 5, pp. 474-487, 2011.

[27] J. S. Czapla-Myers, K. J. Thome, and S. F. Biggar, "Design, calibration, and characterization of a field radiometer using light-emitting diodes as detectors," Appl. Opt., vol. 47, no. 36, pp. 6753-6762, 2008.

[28] K. Novick, R. Oren, P. Stoy, J.-Y. Juang, M. Siqueira, and G. Katul, "The relationship between reference canopy conductance and simplified hydraulic architecture," Advances in Water Resources, vol. 32, pp. 809-819, 2009.

[29] R. Oren, C. I. Hsieh, P. Stoy, J. Albertson, H. R. McCarthy, P. Harrell, and G. G. Katul, "Estimating the uncertainty in annual net ecosystem carbon exchange: Spatial variation in turbulent fluxes and sampling errors in eddy-covariance measurements," Global Change Biol., vol. 12, pp. 883-896, 2006.

[30] D. J. Bremer and J. M. Ham, "Net carbon fluxes over burned and unburned native tallgrass prairie," Rangeland Ecol. Manage., vol. 63, pp. 72-81, 2010.

[31] N. A. Brunsell, S. Schymanski, and A. Kleidon, "Quantifying the thermodynamic entropy budget of the land surface: Is this useful?," Earth System Dynamics, vol. 2, pp. 87-103, 2011, 10.5194/esd-2-87-2011.

[32] N. A. Brunsell, J. B. Nippert, and T. L. Buck, "The impact of seasonality and surface heterogeneity on water use efficiency in mesic grasslands," Ecohydrology, 2013, in review.

[33] T. M. Scanlon and J. D. Albertson, "Canopy scale measurements of $\mathrm{CO}_{2}$ and water vapor exchange along a precipitation gradient in southern Africa," Global Change Biol., vol. 10, no. 3, pp. 329-341, 2004. 
[34] R. J. Scholes, P. R. Dowty, K. Caylor, D. A. B. Parsons, P. G. H. Frost, and H. H. Shugart, "Trends in savanna structure and composition on an aridity gradient in the Kalahari," J. Veg. Sci., vol. 13, pp. 419-428, 2002.

[35] R. J. Scholes, P. G. H. Frost, and Y. H. Tian, "Canopy structure in savannas along a moisture gradient on Kalahari sands," Global Change Biol., vol. 10, pp. 292-302, 2004.

[36] ENVI, Environment for Visualizing Images, Image Processing Software, ver. 4.7, 2009, Research Systems, Inc., ITT Visual Information Solutions. Boulder, CO, USA [Online]. Available: www.ittvis.com

[37] ERDAS Imagine 2010. ERDAS: Earth Resources Data Analysis System 2009, ERDAS, Inc.. Norcross, GA, USA.

[38] R. F. Kokaly, PRISM: Processing routines in IDL for spectroscopic measurements (Installation Manual and User's Guide, ver. 1.0), U.S. Geological Survey Open-File Report 2011-1155, 432, 2011.

[39] Atmosphere CORrection Now (ACORN v. 6.1b), (C) 2004-08 ImSpec LLC, "Analytical Imaging and Geophysics LLC (AIG)," 2001, ACORN User's Guide Stand Alone Version, 64 p.

[40] A. Berk, G. P. Anderson, L. S. Bernstein, P. K. Acharya, H. Dothe, M. W. Matthew, S. M. Adler-Golden, J. H. Chetwynd, Jr., S. C. Richtsmeier, B. Pukall, C. L. Allred, L. S. Jeong, and M. L. Hoke, "MODTRAN4 radiative transfer modeling for atmospheric correction," SPIE Proc. 3756, Optical Spectroscopic Techniques and Instrumentation for Atmospheric and Space Research III, 1999.

[41] A. A. Bannari, K. Omari, P. M. Teillet, and G. Fedosejevs, "Multisensor and multiscale survey and characterization for radiometric spatial uniformity and temporal stability of Railroad Valley Playa (Nevada) test site used for optical sensor calibration," Proc. SPIE 5234 , p. 590, 2004.

[42] D. Baldocchi, "TURNER REVIEW No. 15. 'Breathing' of the terrestrial biosphere: Lessons learned from a global network of carbon dioxide flux measurement systems," Australian J. Botany, vol. 56, no. 1, pp. 1-26, 2008.

[43] P. C. Stoy, G. G. Katul, M. B. S. Siqueira, and J.-Y. Juang, "An evaluation of models for partitioning eddy covariance-measured net ecosystem exchange into photosynthesis and respiration," Agricultural and Forest Meteorology, vol. 141, pp. 2-18, 2006.

[44] B. D. Amiro, A. G. Barr, T. A. Black, H. Iwashita, N. Kljun, J. H. McCaughey, K. Morgenstern, S. Murayama, Z. Nesic, A. L. Orchansky, and N. Saigusa, "Carbon, energy and water fluxes at mature and disturbed forest sites, Saskatchewan, Canada," Agricultural and Forest Meteorology, no. 136, pp. 237-251, 2006.

[45] M. Reichstein et al., "On the separation of net ecosystem exchange into assimilation and ecosystem respiration: Review and improved algorithm," Global Change Biol., vol. 11, no. 9, pp. 1424-1439, 2005.

[46] R. F. Kokaly and R. N. Clark, "Spectroscopic determination of leaf biochemistry using band-depth analysis of absorption features and stepwise multiple linear regression," Remote Sens. Environ., vol. 67, pp. 267-287, 1999

[47] R. N. Clark and T. L. Roush, "Reflectance spectroscopy: Quantitative analysis techniques for remote sensing applications," J. Geophys. Res., vol. 89, no. B7, pp. 6329-6340, 1984, 10.1029/JB089iB07p06329.

[48] O. Mutanga, A. K. Skidmore, and H. H. T. Prins, "Predicting in situ pasture quality in the Kruger National Park, South Africa, using continuum-removed absorption features," Remote Sens. Environ., vol. 89 , pp. 393-408, 2004

[49] “SYSTAT 12, Version 12.02.00," SYSTAT Software, Inc., San Jose, CA, USA, 2007

[50] F. Baret, M. Weiss, D. Allard, S. Garrigues, M. Leroy, H. Jeanjean, R. Fernandes, R. B. Myneni, J. T. Morissette, J. Privette, H. Bohbot, R. Bosseno, G. Dedieu, C. Di Bella, M. Espana, V. Gond, X. F. Gu, D. Guyon, C. Lelong, P. Maisongrande, E. Mougin, T. Nilson, F. Veroustraete, and R. Vintilla, "VALERI: A network of sites and a methodology for the validation of medium spatial resolution land satellite product," Remote Sens. Environ. [Online]. Available: http://w3.avignon.inra.fr/ valeri/documents/VALERI-RSESubmitted.pdf

[51] M. E. Brown, J. E. Pinzon, K. Didan, J. T. Morisette, and C. J. Tucker, "Evaluation of the consistency of long-term NDVI time series derived from AVHRR, SPOT-vegetation, SeaWiFS, MODIS, and Landsat ETM+ sensors," IEEE Trans. Geosci. Remote Sens., vol. 44, no. 7, pp. $1787-1793,2006$.

[52] S. Garrigues, R. Lacaze, F. Baret, J. T. Morisette, M. Weiss, J. Nickeson, R. Fernandes, S. Plummer, N. V. Shabanov, R. Myneni, and W. Yang, "Validation and intercomparison of global leaf area index products derived from remote sensing data," J. Geophys. Res., vol. 113, no. G2, p. G02028, 2008, 10.1029/2007JG000635.
[53] J. A. Gamon, Y. Cheng, H. Claudio, L. MacKinney, and D. Sims, "A mobile tram system for systematic sampling ecosystem optical properties," Remote Sens. Environ., vol. 103, pp. 246-254, 2006.

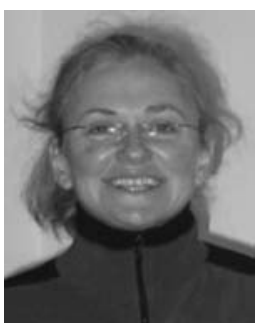

Petya K. Entcheva Campbell (M'99) received the B.S. degree in forest engineering and silviculture from the University of Forestry, Sofia, Bulgaria, the M.S. degree in forest ecology from the University of Massachusetts, Amherst, MA, USA, and the $\mathrm{Ph} . \mathrm{D}$. degree in forest analysis/remote sensing from University of New Hampshire, Durham, NH, USA.

Currently she is a Research Assistant Professor at the Joint Center for Earth Systems Technology, University of Maryland Baltimore County (UMBC). She is affiliated with the Department of Geography and Environmental Systems at UMBC, where she has taught GES481/681 undergraduate/graduate classes in "Remote sensing for environmental applications". She is a research associate at the Biospheric Sciences Laboratory at NASA Goddard Space Flight Center (GSFC), Greenbelt, MD, USA.

Her research focuses on remote sensing of vegetation bio-physical parameters and function for assessing ecosystem processes and dynamics, conducting spectral reflectance and fluorescence analyses and using satellite, airborne, field and laboratory measurements. At GSFC she contributes to the research of spectral bio-indicators of vegetation function, and participates in the Mission Science team for the Earth Exploring One (EO-1). Dr. Campbell is a member of American Society for the Advancement of Science (AAAS), Geoscience \& Remote Sensing Society (IEEE GRSS), International Association for Landscape Ecology (IALE), Society of American Foresters (SAF), and has previously served as the Technical Secretariat for the WGCV/CEOS.

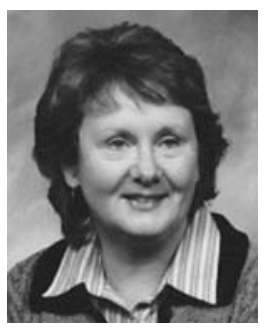

Elizabeth M. Middleton received the B.S. degree in zoology from the University of Maryland in 1967, the M.S. degree in ecology from the University of Maryland in 1976, and the Ph.D. degree in botany from the University of Maryland in 1993.

Dr. Middleton is a Senior Scientist with the Laboratory for Biospheric Sciences (new Code 618 ) at NASA/GSFC, Greenbelt, MD. She is currently the Mission Scientist for the Earth Exploring One (EO-1) satellite and the GSFC lead for the NASA HyspIRI satellite concept development. Dr. Middleton recently received in 2011 a Career Achievement Award from the Hydrospheric and Biospheric Sciences Laboratory at GSFC. She also received NASA Group Achievement Awards in 1983, 1994, 1995 and 2003, respectively, in addition to numerous Performance Awards. She has previously served, and is currently serving, as the Outside Observer on the Mission Advisory Group (2007-2009, 2011+) for a European Space Agency's Phase A satellite mission concept- the FLuorescence Explorer (FLEX). In addition, she was a member of NASA/GSFC Carbon Cycle Science Working Group (2000-2007) and the NASA representative to the US Federal Geographic Data Committee's Vegetation Subcommittee for many years. Dr. Middleton leads a research team that studies vegetation spectral bio-indicators of plant stress and photosynthetic function, including plant fluorescence. She is Associate Editor of the Journal of Applied Remote Sensing.

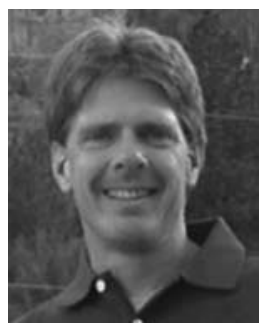

Kurt J. Thome received the B.S. degree in meteorology from Texas A\&M University and the M.S. and Ph.D. degrees in atmospheric sciences from the University of Arizona. He then joined what is now the College of Optical Sciences, becoming full Professor in 2006.

He served as the Director of the Remote Sensing Group from 1997 to 2008. He moved to NASA's Goddard Space Flight Center in 2008 as a Physical Scientist in the Biospheric Sciences Branch. He has been a member of the Landsat-7, ASTER, MODIS, and EO-1 Science Teams providing vicarious calibration results for those and other imaging sensors. He is a Fellow of SPIE, is the Instrument Scientist for the Visible Infrared Imaging Radiometer Suite on the Joint Polar Satellite System and is serving as the calibration lead for the Thermal Infrared Sensor on the Landsat Data Continuity Mission. Dr. Thome is the Deputy Project Scientist for CLARREO for which he is also the instrument lead for the Reflected Solar Instrument. 
Raymond F. Kokaly (M'07) received his B.S. degree in Aerospace Engineering from the University of Texas at Austin in 1991 and his M.S. in Aerospace Engineering Sciences from the University of Colorado at Boulder in 1993. From 1994 to 1996, he was a Professional Research Assistant at the National Snow and Ice Data Center at the University of Colorado at Boulder. Since 1996, he has been a Research Geophysicist at the U.S. Geological Survey in Denver, Colorado. His research generally focuses on characterizing vegetation and other organic substances with spectroscopy and the development of spectroscopic methods of remote sensing for biologic, geo-botanical and environmental studies. His applications of hyperspectral remote sensing data also include the identification of bedrock and soil mineralogy using imaging spectrometer data. He is a member of the American Geophysical Union (AGU), the American Society for Photogrammetry and Remote Sensing (ASPRS), and the Society of Photo-Optical Instrumentation Engineers (SPIE).

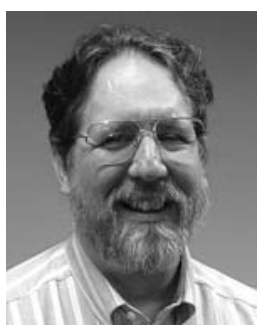

Karl Fred Huemmrich received the B.S. in physics from Carnegie-Mellon University and a Ph.D. in geography from the University of Maryland, College Park. Presently he is a Research Associate Professor in the Joint Center for Earth Systems Technology at the University of Maryland Baltimore County and works in the Biospheric Sciences Laboratory at Goddard Space Flight Center. His work involves determining biophysical variables using remote sensing, combining both models and field measurements. He worked on a number of field studies including the First International Satellite Land Surface Climatology Project Field Experiment (FIFE) and Boreal Ecosystem and Atmosphere Study (BOREAS)

David Lagomasino was born in Athens, GA and moved to Miami, FL as a young boy. While in Florida, he graduated with a B.S. in geological sciences from Florida International University. He then continued his education at East Carolina University in Greenville, NC and earned a M.S. in geology. After earning his M.S., he then moved back to Florida and to his alma mater to pursue a Ph.D. in geological sciences. During his time at ECU, David was a Research Assistant in the Oceanography and Radioactive Isotope Laboratories and focused primarily of wetland sedimentation and coastal processes. Currently, he is a Research Assistant in the Hydrogeology Lab at FIU, where he combines water chemistry and remote sensing. His research areas include the sedimentology and ecohydrology of coastal wetlands and estuaries, with particular interest in remote sensing and groundtruthing. Mr. David Lagomasino is a member of American Geophysical Union and Geological Society of America.

Kimberly A. Novick was born in Montgomery County, Maryland. Novick received a B.S.E in Civil and Environmental Engineering from Duke University (Durham, NC, USA) in 2002, and Ph.D in environmental science from the Nicholas School of the Environmental at Duke University in 2010. She is currently an assistant professor at the School of Public and Environmental Affairs (SPEA) at Indiana University (Bloomington, IN, USA). From 2010-2012, she worked as a research ecologist with the USDA Forest Service Southern Research Station, based at the Coweeta Hydrologic Laboratory. Her research is focused on quantifying and modeling the biosphere-atmosphere exchange of mass and energy. Her most recent work is focused on methodological approaches for interpreting eddy covariance flux measurements over complex terrain, and theoretical approaches to describe host resistance to bark beetle herbivory. Dr. Novick is a member of the American Geophysical Union.

Nathaniel A. Brunsell received his B.S. degree from the University of New Mexico in Earth and Planetary Sciences and his Ph.D. from Utah State University in Biometeorology. He was a post-doctoral research associate at Duke University from 2002-2004.

Since 2004, he has been in the Dept. of Geography at the University of Kansas where he is currently an associate professor. His research generally focuses on land-atmosphere exchange processes and the role of spatial and temporal heterogeneity on these fluxes. He utilizes a range of modeling, field observations and satellite data. 